\title{
Long-Lived Metastable States and Hysteresis in the Binding of Acetylcholine to Torpedo californica Acetylcholine Receptor ${ }^{\dagger}$
}

\author{
Hai Won Chang, ${ }^{*}$ Ernest Bock, and Eberhard Neumann ${ }^{\ddagger}$
}

\begin{abstract}
Studies of the binding of $\left[{ }^{3} \mathrm{H}\right]$ acetylcholine to receptor-rich membranes of Torpedo californica electric organ under conditions that normally lead to a state of equilibrium did not give rise to equilibrium binding curves. Instead, the acetylcholine receptor was found to develop very long lived metastable states resulting in hysteresis in binding. Under conditions where the concentration of free $\left[{ }^{3} \mathrm{H}\right]$ acetylcholine is both less than $0.1 \mu \mathrm{M}$ and smaller or comparable to the total receptor concentration, the degree of binding of acetylcholine depends on the rate, i.e., the mode, of increasing the acetylcholine concentration (rapid mixing vs. dialysis). The equilibrium positive cooperativity in high-affinity acetylcholine binding previously inferred from the data is deceiving; the curvature in Scatchard representations is a consequence of long-lived nonequilibrium distributions between high-affinity and lower affinity receptor conformers. By manipulation of the experimental conditions, true equilibrium binding, resulting in a linear Scatchard binding curve, was obtained and yielded the apparent equilibrium constant, $\bar{K}=5 \pm 1 \mathrm{nM}$ at $4^{\circ} \mathrm{C}$. The stoichiometry of the high-affinity site associated with this $\vec{K}$ value was found to be one acetylcholine per receptor monomer $\left(M_{\mathrm{r}} 250000\right)$ when carefully standardized [ $\left.{ }^{3} \mathrm{H}\right]-$ acetylcholine analyzed for both radiopurity and acetylcholine concentration was used. While our fresh membrane fragments prepared in the presence of $4 \mathrm{mM} \mathrm{Ca}^{2+}$ revealed up to twice as many ${ }^{125} \mathrm{I}-\alpha$-bungarotoxin sites in $0.1 \%$ nonionic detergent relative to those assayed in the absence of detergent, nonionic
\end{abstract}

he binding of acetylcholine $(\mathrm{AcCh})^{1}$ ( $\mathrm{A}$ in equations and schemes) by the acetylcholine receptor ( $A c C h R ; R$ in equations and schemes) is a key reaction in the chemical control of the bioelectric excitation of cholinergic membranes [for monographs, see Nachmansohn (1959) and Katz (1969)]. The nicotinic AcChR protein of fish electric organs, which regulates the rapid $\mathrm{Na}^{+}-\mathrm{K}^{+}$fluxes through the electroplax membranes, exhibits major conformational variability consistent with its functional properties [for recent reviews, see Karlin (1980), Changeux (1981), Adams (1981), Conti-Tronconi \& Raftery (1982) and Taylor et al. (1983)]. Electrophysiological data from frog neuromuscular junctions, which in their electrical-chemical behavior are similar to that of fish electric organs, suggested that the AcChR channel coexists in at least two conformational states prior to any AcCh binding: an activatable resting state $\left(R_{1}\right)$ and an inactivated desensitized state $\left(R_{h}\right)$ with a binding affinity for $\mathrm{AcCh}$ that is higher than that

\footnotetext{
${ }^{\dagger}$ From the Department of Neurology, College of Physicians and Surgeons, Columbia University, New York, New York 10032 (H.W.C. and E.B.), and the Max-Planck-Institut für Biochemie, Martinsried bei München, Federal Republic of Germany (E.N.). Received November 18, 1983; revised manuscript received March 20, 1984. This investigation was supported by the National Institutes of Health (Grant 5-R01NS-13744), the Muscular Dystrophy Association of America, and the Deutsche Forschungsgemeinschaft (Grant NE 227/3-5).

$\ddagger$ Present address: Department of Biophysical Chemistry, University of Bielefeld, Bielefeld, Federal Republic of Germany (D-4800).
}

detergent treatment of membrane fragments did not result in any change in total available acetylcholine binding sites. Therefore, we favor the interpretation either that the detergent loosens the membrane and exposes a second sterically hindered $\alpha$-toxin binding site or that it increases its affinity. Our $\left[{ }^{3} \mathrm{H}\right]$ acetylcholine binding data with solubilized and purified acetylcholine receptor predominantly in the covalently linked dimeric form $(13 \mathrm{~S})$ are qualitatively very similar to those with membrane-bound receptor and indicate that the very high affinity state is induced by acetylcholine during dialysis rather than being a preexisting conformation. The relative stoichiometry of acetylcholine binding sites of purified receptor with $\tilde{K}=4 \pm 1 \mathrm{nM}$ to $\alpha$-bungarotoxin binding sites is close to 0.5 , the same as that found in membrane fragments when the value of ${ }^{125} \mathrm{I}$ - $\alpha$-bungarotoxin binding sites assayed in the presence of nonionic detergent is used. The smallest cooperative element to account for the dialysis and rapid-mixing data is the receptor dimer, and this form is introduced in the proposed reaction scheme. The hysteresis in the acetylcholine binding to the receptor is associated with a free-energy dissipation of $\Delta G_{\text {irt }}=-2.8( \pm 0.1) \mathrm{kJ} \mathrm{mol}^{-1}$ and an entropy production of $\Delta_{i} S=10.1( \pm 0.4) \mathrm{J} \mathrm{K}^{-1} \mathrm{~mol}^{-1}$, per concentration-dilution cycle at $4{ }^{\circ} \mathrm{C}$. The capacity to develop long-lived metastable states may be a saving device to maintain receptors in the activatable low-affinity conformation. The hysteresis classified the receptor as a memory molecule which can reflect previous exposure to acetylcholine.

of the activatable conformation [for a review, see Magazanik \& Vyskocil (1976) and Nastuk (1977)]. Prolonged application of $\mathrm{AcCh}$ is presumed to shift the preexisting two-state equilibrium to the side of the desensitized complex, according to a cyclic scheme [Katz \& Thesleff, 1957; see also Rang \& Ritter (1970)]:

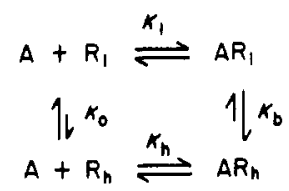

where the overall equilibrium dissociation constant $(\bar{K})$ for the ligand $\mathrm{A}$ is given by $\bar{K}=K_{1}\left(1+K_{0}\right) /\left(1+K_{\mathrm{b}}\right)$.

A cyclic reaction scheme is also required to describe the activation-inactivation process of the ${ }^{22} \mathrm{Na}^{+}$transport measured in vitro with receptor-rich membrane vesicles (Sugiyama et al., 1976; Bernhardt \& Neumann, 1978; Neubig \& Cohen, 1980; Neubig et al., 1982). Furthermore, the observation of agonist-induced, practically complete ${ }^{22} \mathrm{Na}^{+}$flux inactivation

\footnotetext{
${ }^{1}$ Abbreviations: $\mathrm{AcCh}$, acetylcholine; $\mathrm{AcChR}$, acetylcholine receptor; AcChE, acetylcholinesterase; $\alpha$-Bgtx, $\alpha$-bungarotoxin; DFP, diisopropyl fluorophosphate; EDTA, ethylenediaminetetraacetic acid; NEM, $N$ ethylmaleimide; PIPES, piperazine- $N, N^{\prime}$-bis (2-ethanesulfonic acid); TLC, thin-layer chromatography; Tetram, $O, O$-diethyl $S$-[2-(diethy]amino)ethyl] phosphorothioate.
} 
observed in conventional flux measurements (Kasai \& Changeux, 1971; Popot et al., 1976) characterizes the openchannel conformer as a transient, metastable state, and the data also imply that the step leading to inactivation must be much faster than the reverse step (Bernhardt \& Neumann, 1978; Neumann \& Bernhardt, 1981; Neubig et al., 1982). Evidence for a slow conformational transition of the AcChR to a higher affinity state had originally been deduced from the effect of agonists on the initial rate of $\alpha$-toxin binding (Weber et al., 1975; Weiland et al., 1976, 1977; Quast et al., 1978). Furthermore, direct $\left[{ }^{3} \mathrm{H}\right] \mathrm{AcCh}$ binding studies by a fast filtration method and by stopped-flow fluorescence technique have provided quantitative descriptions of conformational equilibria between the low-affinity and the higher affinity conformers (Boyd \& Cohen, 1980a; Barrantes, 1978; Heidmann \& Changeux, 1979). Recent data of ${ }^{22} \mathrm{Na}$ efflux from membrane vesicles obtained on a relatively fast time scale revealed that there are several types of low-affinity conformations associated with an overall $\mathrm{AcCh}$ equilibrium constant of $\bar{K} \sim 10^{-6} \mathrm{M}$. Among these are the activatable resting state, the ion-transporting conformation, and a desensitized intermediate structure of transient nature (Neubig \& Cohen, 1980; Neubig et al., 1982). Furthermore, electrophysiological studies suggest that the desensitization process itself is complex in that it comprises at least two processes (Sakmann et al., 1980; Clark \& Adams, 1981; Feltz \& Trautmann, 1982; Chesnut, 1983).

In direct binding studies with $\left[{ }^{3} \mathrm{H}\right] \mathrm{AcCh}$ under equilibrium conditions, the data presumably represent the binding properties of a desensitized $\mathrm{AcChR}$, either preexisting in that form or desensitized during the binding. With receptor-rich membrane fragments, an overall equilibrium constant of $\bar{K}=10-40$ nM either with positive cooperativity (Weber \& Changeux, 1974b; Damle et al., 1976; Schiebler et al., 1977; Eldefrawi et al., 1978; Neubig \& Cohen, 1979; Fels et al., 1982) or without cooperativity (Raftery et al., 1975; Sugiyama \& Changeux, 1975; Blanchard et al., 1982) has been reported. While some laboratories report $l$ of these high-affinity $\mathrm{AcCh}$ binding sites per $\alpha$-toxin site, others have found a ratio of 0.5 [see reviews by Changeux (1981) and Taylor et al. (1983)].

In the course of our $\left[{ }^{3} \mathrm{H}\right] \mathrm{AcCh}$ binding studies with membrane-bound $\mathrm{AcChR}$ under the usual equilibrium binding conditions, we observed large variations among different sets of binding data caused by changes in conditions which in typical equilibrium systems should not influence the binding parameters. Specifically, differences were observed when the rate, i.e., mode, of applying $\left[{ }^{3} \mathrm{H}\right] \mathrm{AcCh}$ to membrane fragments was changed, when the time of exposure to $\left[{ }^{3} \mathrm{H}\right] \mathrm{AcCh}$ during equilibrium dialysis was altered, or when different concentrations of receptor samples were used. Such unexplained variabilities in the $\left[{ }^{3} \mathrm{H}\right] \mathrm{AcCh}$ binding curve had previously been reported by other laboratories for detergent-solubilized AcChR (O'Brien \& Gibson, 1975; Gibson, 1976). Here we report the novel finding that binding of $\left[{ }^{3} \mathrm{H}\right] \mathrm{AcCh}$ both to membrane-bound and to solubilized and purified AcChR does not in the general case yield a true equilibrium curve but exhibits hysteresis, suggesting that long-lived metastable states of at least two different high-affinity receptor states are involved. Therefore, the often reported sigmoidal shape of $\left[{ }^{3} \mathrm{H}\right] \mathrm{AcCh}$ binding curves and the upward curvature of Scatchard plots [for reviews, see Changeux (1981) and Karlin (1980)] are not due to equilibrium positive cooperativity as previously thought but rather to long-lived nonequilibrium distributions of high-affinity and lower affinity conformers. A reaction scheme which accounts for the experimental data is proposed, and its physiological significance in relation to receptor desensitization is discussed.

\section{Materials and Methods}

Materials. Electric organ tissue removed from Torpedo californica, received live from Pacific Bio-Marine Laboratories, Inc., Venica, CA, was stored in liquid nitrogen. The nonionic detergent Lubrol WX was obtained from Sigma Chemical Co., and a $10 \%(\mathrm{w} / \mathrm{v})$ aqueous solution with $0.01 \mathrm{mM}$ EDTA was prepared, stored $24 \mathrm{~h}$ at $4^{\circ} \mathrm{C}$, and centrifuged $15 \mathrm{~min}$ at $48000 \mathrm{~g}$ to remove insoluble material. Diisopropyl fluorophosphate (DFP) was obtained from Sigma Chemical Co. Ten-microliter aliquots were sealed in capillary tubes and stored at $-20^{\circ} \mathrm{C}$. From these, $10 \mathrm{mM}$ stock solutions were prepared in anhydrous propylene glycol and stored in a desiccator at $-20^{\circ} \mathrm{C}$. Gallamine triethiodide (Flaxedil) was purchased from ICN Life Sciences Group. Tetram $[0,0$. diethyl $S$-[2-(diethylamino)ethyl] phosphorothioate] was synthesized by the method of either Calderbank \& Gosh (1955) or Fukuto \& Stafford (1957). Stock solutions (0.5-1 $\mathrm{mM})$ in $\left[\right.$ acetyl $\left.{ }^{3} \mathrm{H}\right]$ acetylcholine chloride $(0.25-2.7 \mathrm{Ci} / \mathrm{mM})$, obtained from the Amersham Corp., were prepared in distilled water. Their exact concentrations were determined by a modified Hestrin (1949) method as described previously (Chang \& Bock, 1979), and the radiochemical purity was ascertained by the thin-layer chromatography (TLC) method of Lewis \& Eldefrawi (1974), except that each TLC sample size for $1-\mathrm{cm}$ width of a silica gel impregnated glass fiber strip (Gelman Instrument $\mathrm{Co}$.) did not exceed $5 \mu \mathrm{L}$ and the sample $(0.1-1 \mu \mathrm{M})$ was prepared in the chromatography solvent $(80 \%$ ethanol). The rate of change in radiochemical purities of $\left[{ }^{3} \mathrm{H}\right] \mathrm{AcCh}$ solutions during storage at $4^{\circ} \mathrm{C}$, presumably largely due to hydrolysis, varied among different lots, but usually $1 \%$ $\pm 0.2 \%$ per month was found in those lots with high initial radiochemical purities. Unless otherwise noted, all experiments were carried out at $0-4{ }^{\circ} \mathrm{C}$.

Preparation of AcChR-Rich Membrane Fragments. The method used was that of Sobel et al. (1977) with some modifications. Ninety grams of liquid nitrogen frozen Torpedo californica electric organ in $120 \mathrm{~mL}$ of buffer I $(10 \mathrm{mM}$ PIPES, pH 7.0, $100 \mathrm{mM} \mathrm{NaCl}, 4 \mathrm{mM} \mathrm{CaCl}$, and $0.5 \mathrm{mM}$ EDTA), containing $3 \mathrm{mM}$ benzamidine hydrochloride, 0.1 $\mathrm{mM}$ bacitracin, and $10 \mu \mathrm{M}$ pepstatin, was homogenized with a Virtis 45 homogenizer for $2 \mathrm{~min}$ at top speed and centrifuged for $10 \mathrm{~min}$ at $3000 \mathrm{~g}$. In some preparations, $0.1-5 \mathrm{mM} \mathrm{N}$ ethylmaleimide or iodoacetamide was included in the initial homogenization buffer to prevent disulfide-sulfhydryl interchange (Chang \& Bock, 1977). The supernatant was decanted through several layers of nylon mesh and respun for $30 \mathrm{~min}$ at $140000 \mathrm{~g}$. The resultant pellet was homogenized with 60 $\mathrm{mL}$ of buffer I for $40 \mathrm{~s}$ at half-maximum speed. The homogenate was placed onto three discontinuous gradients in Beckman SW 28 rotor centrifuge tubes, each consisting of 6 $\mathrm{mL}$ of $42 \%$ sucrose, $7 \mathrm{~mL}$ of $37 \%$ sucrose, and $7 \mathrm{~mL}$ of $30 \%$ sucrose solutions prepared with buffer I, and centrifuged for $90 \mathrm{~min}$ at $140000 \mathrm{~g}\left(28000^{\circ} \mathrm{rpm}\right)$. The membrane fragment bands at the three interfaces (bands 1, 2, and 3 from the top to the bottom of the gradient) were collected separately, and corresponding bands from the three gradients were pooled. Each pool was diluted to $75 \mathrm{~mL}$ with buffer I and centrifuged in two SW 28 centrifuge tubes for $30 \mathrm{~min}$ at $140000 \mathrm{~g}$. The tubes were decanted, and each pair of pellets was removed with the aid of $10 \mathrm{~mL}$ of fresh buffer I with $3 \mathrm{mM} \mathrm{NaN}_{3}$ and homogenized for $40 \mathrm{~s}$ at half-maximum speed. The three suspensions thus derived were assayed for $\alpha$-bungarotoxin $(\alpha$-Bgtx) binding site and total protein concentrations and for acetylcholinesterase activity. The suspension derived from the 
band at the $42 \%-37 \%$ sucrose interface (band 3 ), which has the highest specific $\alpha$-Bgtx binding activity, was incubated overnight with $0.2 \mathrm{~mL}$ of $10 \mathrm{mM}$ DFP in anhydrous propylene glycol and then pelleted and resuspended in fresh buffer I with $3 \mathrm{mM} \mathrm{NaN}_{3}$.

Extraction and Purification of AcChR. One hundred grams of liquid nitrogen frozen Torpedo electric organ was homogenized with $300 \mathrm{~mL}$ of $20 \mathrm{mM}$ PIPES buffer, pH 6.8, containing $4 \mathrm{mM} \mathrm{CaCl}_{2}, 5 \mathrm{mM} \mathrm{NEM}, 3 \mathrm{mM}$ benzamidine hydrochloride, and $0.1 \mathrm{mM}$ bacitracin and centrifuged $50 \mathrm{~min}$ at $25000 \mathrm{~g}$. The residue was resuspended in $300 \mathrm{~mL}$ of $10 \mathrm{mM}$

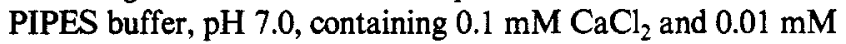
EDTA and centrifuged $30 \mathrm{~min}$ at $25000 \mathrm{~g}$. Membrane proteins were extracted by shaking the residue $>1.5 \mathrm{~h}$ with $50 \mathrm{~mL}$ of $1.5 \%$ Lubrol WX. One hundred milliliters of $10 \mathrm{mM}$ PIPES, $\mathrm{pH} 7.0,1.5 \mathrm{mM} \mathrm{CaCl}_{2}$, and $0.01 \mathrm{mM}$ EDTA was then added, and this suspension was centrifuged for $1 \mathrm{~h}$ at $46000 \mathrm{~g}$. The crude receptor extract thus obtained was purified by affinity chromatography essentially as described previously (Chang \& Bock, 1979).

Assays. The number of ${ }^{125} \mathrm{I}-\alpha-\mathrm{Bgtx}$ binding sites was determined by the DE-81 (Whatman) filter disk method as previously described (Chang \& Bock, 1977) except that a $50-\mu \mathrm{L}$ aliquot of sample which had been incubated overnight with a 3-4-fold excess of ${ }^{125} \mathrm{I}-\alpha$-Bgtx $(>0.2 \mu \mathrm{M})$ in $0.5 \mathrm{mg} / \mathrm{mL}$ bovine serum albumin (BSA) was applied onto a $2.5-\mathrm{cm}$ diameter disk. In the case of AcChR-rich membrane fragments, samples, as well as controls preincubated with a 10 -fold excess of cold toxin, were incubated with ${ }^{125} \mathrm{I}-\alpha$-Bgtx in both in $a b$ sence and presence of $0.1 \%$ Triton X-100. In all cases, the filters were washed individually on the Büchner funnel by gentle suction with ten aliquots of $2.5 \mathrm{~mL}$ of wash solution (10 mM PIPES, pH 7.4, $30 \mathrm{mM} \mathrm{NaCl}$, and $0.02 \%$ Triton $\mathrm{X}-100$ ) and placed in a scintillation vial to which $0.5 \mathrm{~mL}$ of wash solution was added. After $1 \mathrm{~h}, 10 \mathrm{~mL}$ of Scintisol (Isolab Inc.) was added.

Acetylcholinesterase activity was assayed by the spectrophotometric method of Ellman et al. (1961) except that $0.005 \%$ Triton X-100 was added to the assay mixture. For Torpedo acetylcholinesterase, 1 activity unit $(1 \mu \mathrm{mol}$ of $\mathrm{AcCh}$ hydrolyzed $/ \mathrm{min}$ ) in the $\mathrm{pH}$ stat assay was found to be equivalent to $2.9 \pm 0.1 \Delta A_{412 \mathrm{~nm}} / \mathrm{min}$ in the Ellman assay $(\mathrm{H}$. W. Chang, A. Kim, E. Bock, and P. Barnett, unpublished results). Total protein concentrations were determined by the method of Lowry et al. (1951).

$\left[{ }^{3} \mathrm{H}\right] \mathrm{AcCh}$ Binding by the Ultracentrifugation Method. Aliquots of $0.3 \mathrm{~mL}$ of DFP-treated membrane fragment suspension, containing a known concentration of $\alpha$-Bgtx binding sites and preincubated for $1 \mathrm{~h}$ with $10^{-4} \mathrm{M}$ Tetram, were mixed with $0.2 \mathrm{~mL}$ by varying concentrations of $\left[{ }^{3} \mathrm{H}\right]-$ $\mathrm{AcCh}$ in buffer I. One hundred microliters of this mixture was removed for liquid scintillation counting, and $350 \mu \mathrm{L}$ was placed into a centrifuge tube ( $0.7-\mathrm{mL}$ nominal capacity) designed for the Beckman SW 50.1 rotor bucket with adaptor (Beckman 305527) and centrifuged for $15 \mathrm{~min}$ at $140000 \mathrm{~g}$ $(33000 \mathrm{rpm})$. The free concentration of $\mathrm{AcCh}$ was calculated from the radioactivity in $100 \mu \mathrm{L}$ of the supernatant relative to standards of known concentration minus the percent of radioactivity not derived from $\left[{ }^{3} \mathrm{H}\right] \mathrm{AcCh}$ in $100 \mu \mathrm{L}$ of solution before centrifugation (total radioactivity). Radiochemical purity of stock $\left[{ }^{3} \mathrm{H}\right] \mathrm{AcCh}$ solutions was determined by TLC on the day of the experiment, and the percent of radioimpurities in selected supernatants with high counts $(>5000$ cpm $/ 5 \mu \mathrm{L}$ ) was checked and found to be not significantly different from the calculated values based on the initial ra- diochemical purity. Bound AcCh concentrations were calculated from the difference between total and free radioactivity. Parallel experiments using membrane fragments which had been preincubated for over $2 \mathrm{~h}$ with a 10 -fold excess of $\alpha$-Bgtx showed an absence of nonspecific AcCh binding.

$\left[{ }^{3} \mathrm{H}\right] \mathrm{AcCh}$ Binding by Equilibrium Dialysis. Samples of either freshly prepared and DFP-treated AcChR-rich membrane fragments or purified $\mathrm{AcChR}$ were diluted to the desired concentration with buffer I and incubated for over $1 \mathrm{~h}$ with $10^{-4} \mathrm{M}$ Tetram. Aliquots of these solutions were sealed into $6 \mathrm{~mm}$ diameter dialysis tubing and dialyzed for specified times against various concentrations of $\left[{ }^{3} \mathrm{H}\right] \mathrm{AcCh}$ in $50 \mathrm{~mL}$ of buffer I with $60 \mu \mathrm{M}$ Tetram. In experiments with purified AcChR, $0.01 \%$ Lubrol WX was added to buffer I. Aliquots (usually $100 \mu \mathrm{L}$ ) of the solutions inside and outside the bag, as well as $\left[{ }^{3} \mathrm{H}\right] \mathrm{AcCh}$ standards of known concentration, were then subjected to scintillation counting. In studies involving receptor-rich membrane fragments, the content of the bag after dialysis was subjected to ultracentrifugation for $15 \mathrm{~min}$ at $140000 \mathrm{~g}$ for an independent determination of the free $\left[{ }^{3} \mathrm{H}\right]$ $\mathrm{AcCh}$ concentration from the counts in the resultant supernatant corrected for the contribution from non- $\left[{ }^{3} \mathrm{H}\right] \mathrm{AcCh}$ radioactivity.

Modes of Introducing $\left[{ }^{3} \mathrm{H}\right] \mathrm{AcCh}$ in Binding Studies with Membrane Fragments. The following three modes of introducing $\left[{ }^{3} \mathrm{H}\right] \mathrm{AcCh}$ to the membrane fragment sample were used:

(A) Pulse Mode. Aliquots of $\left[{ }^{3} \mathrm{H}\right] \mathrm{AcCh}$ solution are directly added to aliquots of membrane fragments and rapidly mixed by vortexing. The pulse mode implies a closed system with respect to $\left[{ }^{3} \mathrm{H}\right] \mathrm{AcCh}$ (fixed amount of total $\left[{ }^{3} \mathrm{H}\right] \mathrm{AcCh}$ ).

(B) Dialysis Mode. $\left[{ }^{3} \mathrm{H}\right] \mathrm{AcCh}$ is introduced to the sample contained in a dialysis bag by slow diffusion through the membrane from a large pool of almost constant $\left[{ }^{3} \mathrm{H}\right] \mathrm{AcCh}$ concentration (condition of equilibrium dialysis). When the solution inside the bag is plain buffer or $\alpha$-Bgtx-blocked, membrane-bound, or detergent-solubilized and purified AcChR, the time required for greater than $98 \%$ equilibration of $\left[{ }^{3} \mathrm{H}\right] \mathrm{AcCh}$ between the inside and outside of the dialysis bags is $1.5-2$ h. For AcChR, the dialysis mode implies an open system with respect to $\left[{ }^{3} \mathrm{H}\right] \mathrm{AcCh}$ fluxes from and to the dialysis bath.

(C) Combination Mode. $\left[{ }^{3} \mathrm{H}\right] \mathrm{AcCh}$ is added to the membrane fragments by the pulse mode, and this mixture is dialyzed either against a given concentration of $\left[{ }^{3} \mathrm{H}\right] \mathrm{AcCh}$ or against plain buffer to yield a much lower final free $\left[{ }^{3} \mathrm{H}\right] \mathrm{AcCh}$ concentration.

In all three modes, the free and bound $\left[{ }^{3} \mathrm{H}\right] \mathrm{AcCh}$ concentrations were determined by the ultracentrifugation method.

Data Analysis. The $\left[{ }^{3} \mathrm{H}\right] \mathrm{AcCh}$ binding data are presented in terms of $B$, the nanomoles of $\mathrm{AcCh}$ bound per nanomole of $\alpha$-Bgtx binding sites assayed. It should be noted that while the number of $\alpha$-Bgtx binding sites found in the absence of detergent was used for the case of membrane fragments, the values for purified receptor were obtained in the presence of $0.1 \%$ nonionic detergent. The binding data have been analyzed and presented by Scatchard representations according to the following equation:

$$
B /[\mathrm{A}]=B_{\mathrm{m}} / \bar{K}-B / \bar{K}
$$

where [A] is the free AcCh concentration, $B_{\mathrm{m}}$ is the value for maximum $\mathrm{AcCh}$ binding, and $\bar{K}$ is the overall equilibrium dissociation constant.

Results

Effect of Nonionic Detergent on the Number of Titratable 
Table I: Characterization of a Representative Preparation of AcChR-Rich Membrane Fragments Isolated by Discontinuous Sucrose Density Gradient Centrifugation

\begin{tabular}{|c|c|c|c|c|c|c|c|}
\hline \multirow[b]{2}{*}{$\begin{array}{l}\text { membrane } \\
\text { fragment }^{a}\end{array}$} & \multirow[b]{2}{*}{$\begin{array}{l}\text { location, } \\
\% \text { sucrose }^{b}\end{array}$} & \multirow[b]{2}{*}{ volume (mL) } & \multicolumn{3}{|c|}{$\alpha$-Bgtx bound ${ }^{c}$} & \multirow[b]{2}{*}{$\begin{array}{c}\mathrm{sp} \mathrm{act.}{ }^{d} \\
(\mathrm{nmol} / \mathrm{mg})\end{array}$} & \multirow[b]{2}{*}{$\begin{array}{c}\text { esterase activity } \\
\text { (units/nmol of } \\
\alpha \text {-Bgtx sites) }\end{array}$} \\
\hline & & & $\begin{array}{c}\text { no detergent } \\
\text { (nmol/mL) }\end{array}$ & $\begin{array}{c}\text { in } 0.1 \% \\
\text { Triton } \\
\text { (nmol } / \mathrm{mL} \text { ) }\end{array}$ & $\begin{array}{c}\% \text { increase } \\
\text { with } \\
\text { detergent }\end{array}$ & & \\
\hline band 1 & $0 / 30$ & 20 & 1.36 & 2.50 & 53 & $0.8(1.2)$ & 33 \\
\hline band 1 & $30 / 37$ & 16 & 1.02 & 1.70 & 67 & $1.1(1.8)$ & 14 \\
\hline band 3 & $37 / 42$ & 16 & 1.52 & 2.96 & 95 & $1.3(2.5)$ & 5 \\
\hline band $3^{f}$ & & 10 & 2.30 & 4.60 & 100 & $1.4(2.8)$ & 0.03 \\
\hline
\end{tabular}

${ }^{a}$ AcCh-rich membrane fragments were prepared from $90 \mathrm{~g}$ of electric organ of Torpedo californica as described under Materials and Methods. Three opaque bands were collected from the region of the interfaces of discontinuous sucrose density gradients. ${ }^{b}$ The location of the band with respect to the sucrose interface; e.g., band 1 from the $0 \% / 30 \%$ sucrose interface. ${ }^{c}$ Nanomoles of ${ }^{125} \mathrm{I}-\alpha$-Bgtx bound, determined by DE-81 filter disk assays, in the absence and presence of $0.1 \%$ Triton X-100. ${ }^{d}$ Specific activity is the apparent number of moles of $\alpha$-Bgtx binding sites determined in the absence or presence of $0.1 \%$ Triton X-100 (values in parentheses) per milligram of protein. 'One enzyme activity unit is nanomoles defined as $1 \mu \mathrm{mol}$ of AcCh hydrolyzed per min. The activity in membrane fragments is expressed as units per nanomoles of ${ }^{125} \mathrm{I}-\alpha$-Bgtx sites assayed in the presence of $0.1 \%$ Triton X-100. ${ }^{\prime}$ DFP treated; see Materials and Methods.

$\alpha-B g t x$ Sites in Receptor-Rich Membrane Fragments. Fractionation of the crude membrane homogenate of Torpedo electric organ in the presence of $4 \mathrm{mM} \mathrm{Ca}^{2+}$ by discontinuous sucrose density gradient centrifugation yields three bands of AcChR-rich membrane fragments and a small pellet (discarded) that differ in the specific activity of $\alpha$-Bgtx binding and in AcChE activity, as shown in Table I. Toxin binding assays of these membrane fractions carried out in the absence of detergent consistently yield values lower than those from membrane samples preincubated with $0.1 \%$ of a nonionic detergent, such as Triton X-100 or Lubrol WX, and the extent of the difference is critically dependent on the particular density gradient fraction analyzed. Bands 1 and 2 typically bind $40-70 \%$ more ${ }^{125} \mathrm{I}-\alpha$-Bgtx in the presence of detergent, and band 3, the densest fraction, consistently, shows an even larger increase that often approaches $100 \%$. However, both the sucrose gradient banding pattern and the extent of the effect of detergents on the $\alpha$-Bgtx binding assays depend on the buffer system employed during membrane preparation, i.e., inclusion of EDTA and the absence of $\mathrm{Ca}^{2+}$ or the use of a high concentration of $\mathrm{NaCl}$ (data not shown). Membrane fragments used for acetylcholine binding studies described in this paper were derived from band 3, the fractions with the lowest esterase activity and the highest specific $\alpha$-Bgtx binding activity among the three bands: $2.5-3 \mathrm{nmol}$ of toxin bound $/ \mathrm{mg}$ of protein when assayed in the presence of detergent, comparable to an earlier report (Sobel et al., 1977).

Inhibition of Acetylcholinesterase Activity for $\left[{ }^{3} \mathrm{H}\right] \mathrm{AcCh}$ Binding. Overnight incubation of membrane fragments (band 3) with $0.2 \mathrm{mM}$ DFP to achieve irreversible inhibition of esterase (aging) reduced the enzyme activity to below $1 \%$ of the initial value (see Table I). Incubation of these DFP-treated membrane fragments with $0.1 \mathrm{mM}$ Tetram and the use of 60-80 $\mu \mathrm{M}$ Tetram in all solutions further reduced the enzyme activity to negligible levels except that some hydrolysis $(1-2 \%)$ was evident (by TLC analysis) when pulse-mode samples (closed system) containin membrane fragments and higher concentrations $\left([\mathrm{A}]_{\text {free }}>50 \mathrm{nM}\right)$ of $\left[{ }^{3} \mathrm{H}\right] \mathrm{AcCh}$ were incubated overnight.

Since our purified AcChR contains only negligible amounts of esterase (Chang \& Bock, 1979), Tetram treatment sufficed to prevent any hydrolysis of $\left[{ }^{3} \mathrm{H}\right] \mathrm{AcCh}$ during binding studies by equilibrium dialysis in a large pool of $\left[{ }^{3} \mathrm{H}\right] \mathrm{AcCh}$ solution.

Effects of Different Modes of Introducing $\left[{ }^{3} \mathrm{H}\right] \mathrm{AcCh}$ on the Binding of $\left[{ }^{3} \mathrm{H}\right] \mathrm{AcCh}$ to Membrane Fragments. Binding data resulting from pulse-mode addition of $\left[{ }^{3} \mathrm{H}\right] \mathrm{AcCh}$ to freshly prepared receptor-rich Torpedo membrane fragments to yield free $\left[{ }^{3} \mathrm{H}\right] \mathrm{AcCh}$ concentrations in the $2-400 \mathrm{nM}$ range typically result in curved Scatchard plots as shown in Figure 1, curve a. Analysis of several similar experiments, assuming a state of overall equilibrium, indicated $\bar{K}_{\mathrm{d}}=20 \pm 4 \mathrm{nM}$ with positive cooperativity (Hill coefficient, $n_{\mathrm{H}}$, of $1.7 \pm 1$ ), consistent with earlier reports (Weber \& Changeux, 1974b; Damle et al., 1976; Schiebler et al., 1977; Eldefrawi et al., 1978; Neubig et al., 1979; Fels et al., 1982). Under these conditions, no significant changes in the free and bound $\left[{ }^{3} \mathrm{H}\right] \mathrm{AcCh}$ concentrations were observed regardless of whether the ultracentrifugation of the incubation mixture was carried out within 30 min or after $17 \mathrm{~h}$ (curve a of Figure 1, closed and open circles). In this case, the measured $B$ values appear to be time independent. However, when the same incubation mixture was placed in a dialysis bag and subjected to the open-system condition afforded by dialysis against buffer containing the same free $\left[{ }^{3} \mathrm{H}\right] \mathrm{AcCh}$ concentration found by the initial ultracentrifugation method, a continuous increase in binding as a function of time occurred, particularly in the low $(<0.1 \mu \mathrm{M})$ $\left[{ }^{3} \mathrm{H}\right] \mathrm{AcCh}$ concentration range, while the maximum value of $B$ remained constant, as indicated by the abscissa intercept of curves a and $c$ in Figure 1. These results suggest that the population of $\mathrm{AcChR}$ in a higher affinity state is increasing during dialysis.

Qualitatively similar results were obtained when the binding studies were carried out under the usual equilibrium dialysis condition where $\left[{ }^{3} \mathrm{H}\right] \mathrm{AcCh}$ is added to only the outside solution (Figure 2). Again, a similar time-dependent increased in $B$ occurred in the low $\left[{ }^{3} \mathrm{H}\right] \mathrm{AcCh}$ concentration range, evidenced by comparing curve $b(3.5 \mathrm{~h})$ and curve $d(23 \mathrm{~h})$ of Figure 2. It is important to note that in the low concentration range, equilibrium between free $\left[{ }^{3} \mathrm{H}\right] \mathrm{AcCh}$ inside and outside the dialysis bag is still not attained even after as long as $23 \mathrm{~h}$ of dialysis time. This is clearly demonstrated in the two Scatchard plots each for the 3.5-h (Figure 2, curves a and b) and the 23-h (Figure 2, curves $c$ and d) time points which differ because the actual free concentration of $\mathrm{AcCh}$, determined by the ultracentrifugation method, is much lower than the concentration in the dialysis bath which is, in the equilibrium dialysis method, assumed to be equal to the free ligand concentration. Furthermore, the concentration of bound $\left[{ }^{3} \mathrm{H}\right]-$ $\mathrm{AcCh}$ has been underestimated in the dialysis method (Figure 2 , curves a and c) since it is inferred from the difference between the total and the free concentrations.

In another experiment, equilibrium dialysis was carried out with all of the $\left[{ }^{3} \mathrm{H}\right] \mathrm{AcCh}$ that was usually introduced into the $50-200 \mathrm{~mL}$ of outside buffer solutions added instead to the $550 \mu \mathrm{L}$ of membrane fragment samples, thus initially exposing the AcChR to a much higher concentration of $\left[{ }^{3} \mathrm{H}\right] \mathrm{AcCh}$ (1-20 $\mu \mathrm{M})$, and then $\left[{ }^{3} \mathrm{H}\right] \mathrm{AcCh}$ was dialyzed out to achieve free concentrations in the 3-400 $\mathrm{nM}$ range. The Scatchard 


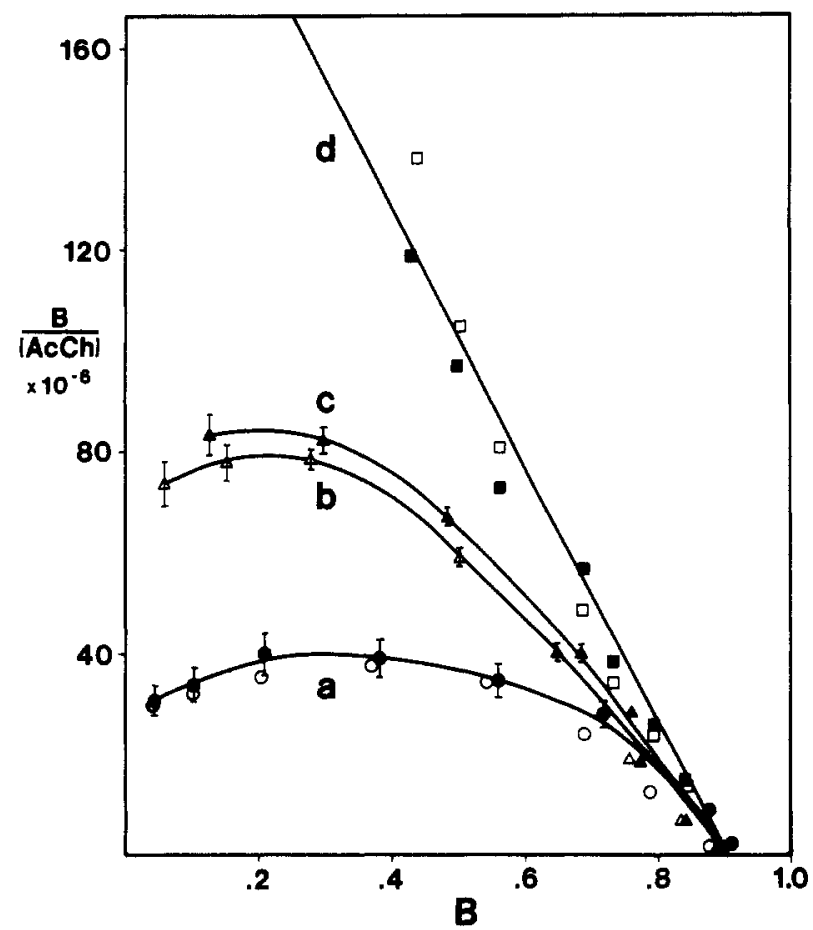

FIGURE 1: Scatchard representation of $\left[{ }^{3} \mathrm{H}\right] \mathrm{AcCh}$ binding to AcChR-rich membrane fragments at $4^{\circ} \mathrm{C}$ arising from different modes of AcCh addition. The same DFP-treated membrane preparation (see Materials and Methods) and the same final receptor concentration ( $0.48 \mu \mathrm{M}$ in $\alpha$-Bgtx binding sites assayed in the absence of detergent) were used in all of these experiments. The buffer composition was $10 \mathrm{mM}$ PIPES (pH 7.0), $4 \mathrm{mM} \mathrm{Ca}^{2+}, 0.5 \mathrm{mM}$ EDTA, $100 \mathrm{mM} \mathrm{NaCl}$, and $0.8 \mu \mathrm{M}$ Tetram. Radiochemical purity was $96 \pm 0.5 \%$ (Amersham batch 39). B is the nanomoles of ligand bound per nanomole of $\alpha$-Bgtx binding sites; $[\mathrm{AcCh}]$ is the molar concentration of free $\left[{ }^{3} \mathrm{H}\right] \mathrm{AcCh}$ at the time of sampling. (a) (b) A fixed amount of varying concentrations of $\left[{ }^{3} \mathrm{H}\right] \mathrm{AcCh}$ was added (pulse mode) to aliquots of the membrane fragment suspension preincubated with $0.1 \mathrm{mM}$ Tetram to give total $\left[{ }^{3} \mathrm{H}\right] \mathrm{AcCh}$ concentrations ranging from $15 \mathrm{nM}$ to $1 \mu \mathrm{M}$. A portion of each sample $(350 \mu \mathrm{L})$ was immediately centrifuged at $140000 \mathrm{~g}$ for $15 \mathrm{~min}$, and concentrations of bound and free $\left[{ }^{3} \mathrm{H}\right] \mathrm{AcCh}$ were determined from the radioactivity in a $100-\mu \mathrm{L}$ solution taken before and after ultracentrifugation and appropriate corrections for radiochemical impurities (see Materials and Methods). Open circles are data points from samples incubated for $17 \mathrm{~h}$ prior to ultracentrifugation. The precision (as indicated by vertical bars) in $B /[\mathrm{A}]$ values arising from uncertainties in radiochemical purity determinations $( \pm 0.5 \%)$ and the radioactivity counting error $(2 \sigma)$ was calculated from $\Delta y= \pm\left\{[(\partial y / \partial B) \Delta B]^{2}+[(\partial y / \partial A) \Delta A]^{2}\right\}^{1 / 2}$ where $y=B /[\mathrm{A}]$. (b) ( $\triangle)$ An aliquot $(550 \mu \mathrm{L})$ of each $\left[{ }^{3} \mathrm{H}\right] \mathrm{AcCh}$-containing sample prepared in (a) was placed in a dialysis bag and dialyzed for $3 \mathrm{~h}$ against buffer containing the concentration of $\left[{ }^{3} \mathrm{H}\right] \mathrm{AcCh}$ determined in (a) to be the free $\left[{ }^{3} \mathrm{H}\right] \mathrm{AcCh}$ concentration. The content of each dialysis bag was then subjected to ultracentrifugation, and the concentrations of free and bound $\left[{ }^{3} \mathrm{H}\right] \mathrm{AcCh}$ were determined as in (a). (c) (A) Same as in (b) except that the dialysis time was 17 $h$. (d) (c) To aliquots of membrane suspension was added $\left[{ }^{3} \mathrm{H}\right] \mathrm{AcCh}$ to give concentrations ranging from 1 to $20 \mu \mathrm{M}$. Each sample (550 $\mu \mathrm{L}$ ) was dialyzed against $25-200 \mathrm{~mL}$ of plain buffer for $17 \mathrm{~h}$ to achieve final free concentrations in the $3-400 \mathrm{nM}$ range. Free and bound $\left[{ }^{3} \mathrm{H}\right] \mathrm{AcCh}$ concentrations were determined from the counts before and after ultracentrifugation. These data yield $\bar{K}=5( \pm 1) \times 10^{-9}$ M. (ם) Same as for (更 except that the free $\left[{ }^{3} \mathrm{H}\right] \mathrm{AcCh}$ concentration was assumed to be equal to the $\left[{ }^{3} \mathrm{H}\right] \mathrm{AcCh}$ concentration of the dialysis buffer outside the bag after $17 \mathrm{~h}$.

plot generated by this experiment (Figure 1, curve d) yielded a straight line with $\bar{K}=5 \pm 1 \mathrm{nM}$ and no indication of positive cooperativity. Furthermore, the free $\left[{ }^{3} \mathrm{H}\right] \mathrm{AcCh}$ concentration, determined by ultracentrifugation of the dialysis bag contents, and radioactivity counting of the supernatant (closed squares), was close to that found in the outside dialysis solution (open squares), indicating that a state of equilibrium had been attained under these conditions. These results show that, in

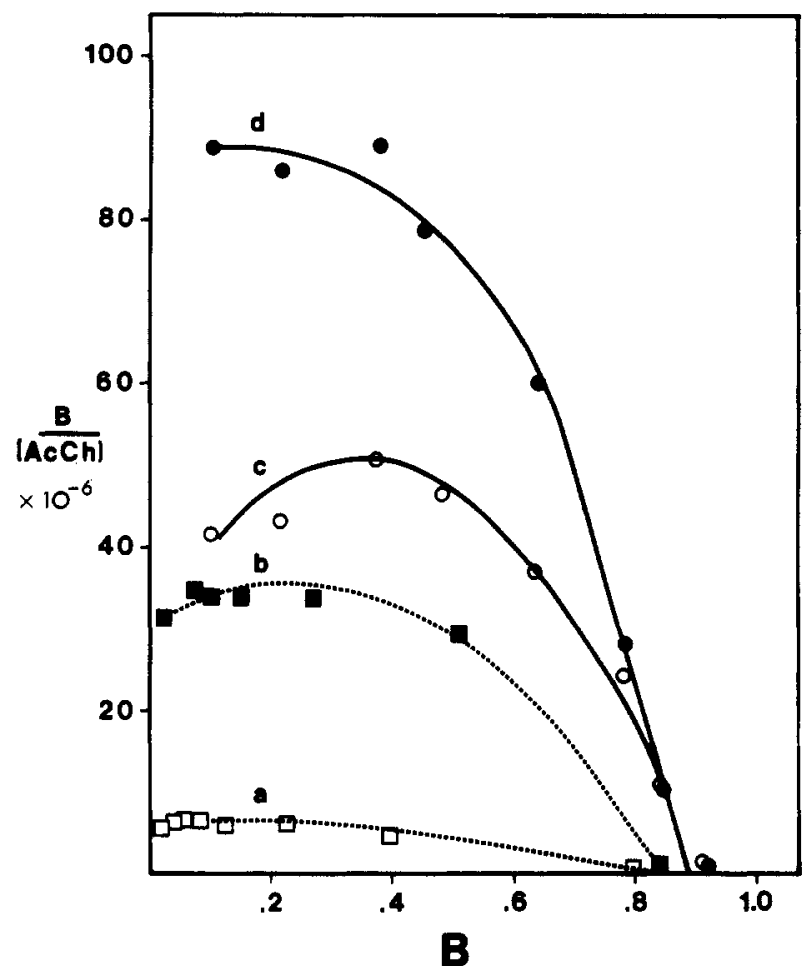

FIGURE 2: Scatchard representations demonstrating the time-dependent increase in the affinity of the receptor for AcCh and the lack of attainment of equilibrium in $\left[{ }^{3} \mathrm{H}\right] \mathrm{AcCh}$ equilibrium dialysis binding studies. Dialysis bags each containing $550 \mu \mathrm{L}$ of receptor-rich membrane fragments $(0.59 \mu \mathrm{M}$ in $\alpha$-Bgtx sites) were subjected to equilibrium dialysis (two bags per flask) against varying $\left[{ }^{3} \mathrm{H}\right] \mathrm{AcCh}$ concentrations. One bag was removed after $3.5 \mathrm{~h} \mathrm{( \cdots )}$ and the other after $23 \mathrm{~h} \mathrm{(-)}$, and [AcCh], the free $\mathrm{AcCh}$ concentration, and $B$, the nanomoles of AcCh bound per nanomole of $\alpha$-Bgtx binding sites, at these times were determined. ( $a$ and $c$ ) The free ligand concentration was assumed to be equal to the concentration of $\left[{ }^{3} \mathrm{H}\right] \mathrm{AcCh}$ in the dialysis bath at the time of sampling. (b and $c$ ) The free AcCh concentration was determined from the radioactivity in the supernatant after ultracentrifugation of the bag contents (see Materials and Methods).

addition to the time element, the transition to the higher affinity state is facilitated by exposure to higher $\mathrm{AcCh}$ concentrations.

The reversibility of the effect of preincubation of the AcChR with a high concentration of $\mathrm{AcCh}$ was examined. The AcChR-rich membrane fragments that had been made $1 \mu \mathrm{M}$ in cold $\mathrm{AcCh}$ and then exhaustively dialyzed against deaerated buffer yielded a curve that was essentially superimposable on the one derived from the same concentration of membrane fragments that had not been exposed to $\left[{ }^{3} \mathrm{H}\right] \mathrm{AcCh}$ (see Figure 1 , curve a).

Time Dependence of $\left[{ }^{3} \mathrm{H}\right] \mathrm{AcCh}$ Binding to Purified AcChR in the Dialysis Mode. In the case of $\mathrm{AcCh}$ binding studies with detergent-solubilized and purified AcChR, it is not possible for us to determine directly the free ligand concentration inside the dialysis bag, such as was done with membrane fragments by using ultracentrifugation. Although an ultrafiltration method (Paulus, 1969) could in principle be utilized, at present we have encountered some technical problems of high blank values and large scatter in trying this approach, and therefore, the concentration of free ligand inside the bag at the time of sampling has been assumed to be equal to that of the outside dialysis solution. The time and concentration dependences observed in the binding of $\left[{ }^{3} \mathrm{H}\right] \mathrm{AcCh}$ with purified AcChR were qualitatively similar to those of membrane fragments and are presented in Figures 3 and 4. Figure 4 shows that although maximum $\left[{ }^{3} \mathrm{H}\right] \mathrm{AcCh}$ binding, 
A

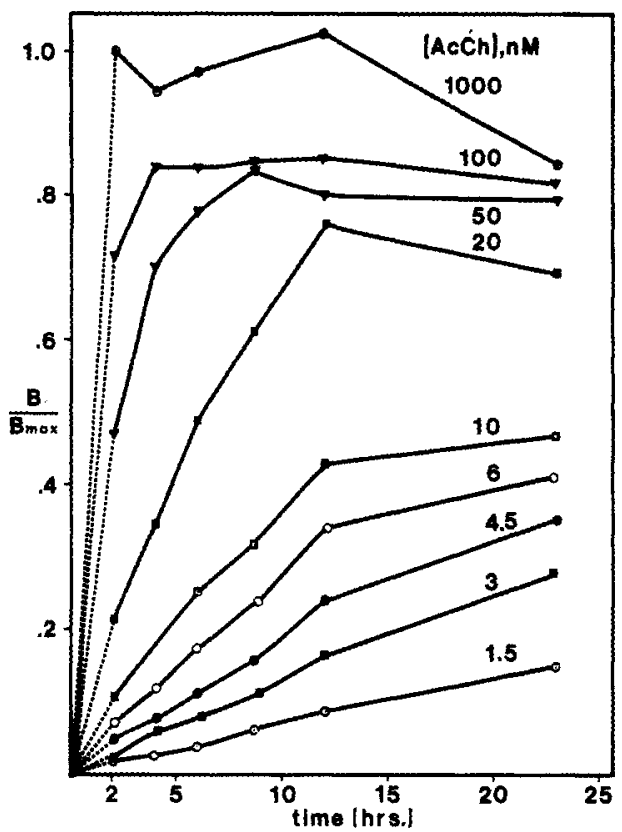

B

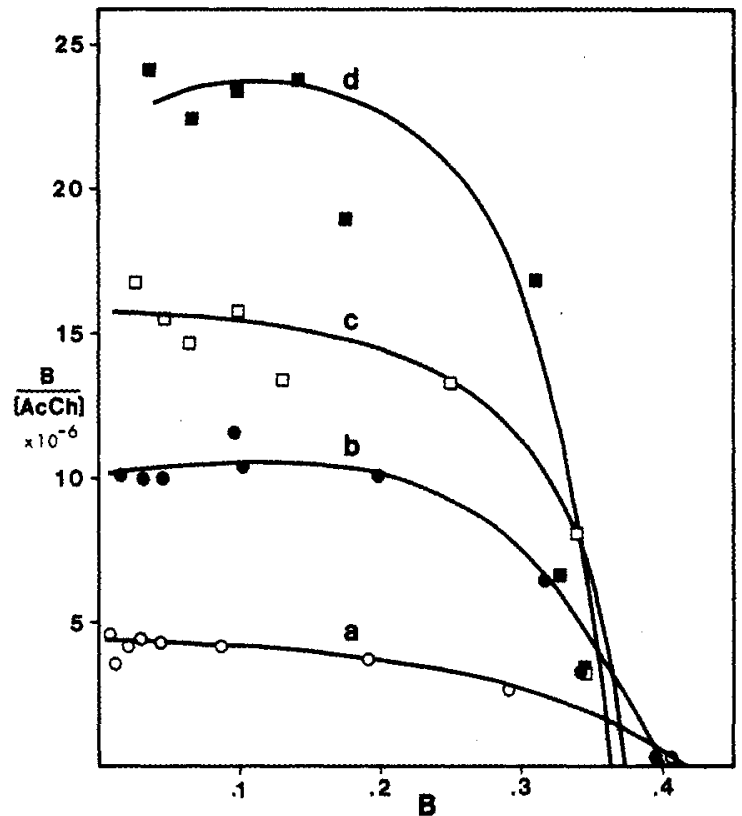

FIGURE 3: (A) Fraction of $\mathrm{AcCh}$ bound $\left(B / B_{\max }\right)$ at a given concentration of purified detergent-solubilized $\mathrm{AcChR}$ (1.6 $\mu \mathrm{M}$ in $\alpha$-Bgtx sites) at various $\mathrm{AcCh}$ concentrations $(1.5-1000 \mathrm{nM})$ at $4^{\circ} \mathrm{C}$ as a function of the dialysis time. The end of the dotted line marks the first time point $(2 \mathrm{~h})$ and the time at which greater than $98 \%$ equilibrium of $\left[{ }^{3} \mathrm{H}\right] \mathrm{AcCh}$ had been achieved in controls. (B) Scatchard representations generated from selected time points in (A): curve a, $2 \mathrm{~h}$; curve $\mathrm{b}, 6 \mathrm{~h}$; curve $\mathrm{c}, 8.5 \mathrm{~h}$; curve d, $12 \mathrm{~h}$.

$0.43 \mathrm{AcCh}$ per $\alpha$-Bgtx site, has already been attained after $2 \mathrm{~h}$, there is a large difference in binding between the 2 - and 19-hr points at lower concentrations. The apparent dissociation constant estimated from the 19-h dialysis data (Figure 4) was $\widetilde{K}=4 \pm 1 \mathrm{nM}$.

As seen in Figure 3A, at a given receptor concentration the fraction of bound $\mathrm{AcCh}$ is a function of dialysis time. Furthermore, the rate of increase in $B / B_{\max }$ to a final time-independent value, presumably the equilibrium value, is faster at higher AcCh concentrations. Below $10 \mathrm{nM}$ AcCh concentration, the maximum value of $B / B_{\max }$ does not appear to have been reached even after $24 \mathrm{~h}$. With still longer dialysis time, a net decrease in $\left[{ }^{3} \mathrm{H}\right] \mathrm{AcCh}$ binding was observed at all AcCh concentrations, probably due to protein denaturation (data not shown). Scatchard representations (Figure 3B) of the same data used to construct Figure 3A clearly demonstrate that, just as in the case of membrane-bound AcChR, a slow progressive increase in the affinity of the purified AcChR for AcCh occurs with dialysis time, and the curvature in the Scatchard plots of Figure 4 suggests that here too true equilibrium binding data were not obtainable even after 19 $\mathrm{h}$ of dialysis.

In our hands, the purified $\mathrm{AcChR}$ in sulfhydryl oxidizing contaminant free $0.01 \%$ Lubrol WX (Chang \& Bock, 1980) and $1 \mathrm{mM} \mathrm{Ca}^{2+}$-containing buffer is mostly $(>85 \%)$ in the covalently linked dimeric form (13 S), retains at least 20 molecules of indigenous phospholipid per $\alpha$-Bgtx binding unit (Chang \& Bock, 1979), and has a specific activity of $\sim 10$ $\mathrm{nmol}$ of $\alpha$-Bgtx binding sites per $\mathrm{mg}$ of protein.

Relative Stoichiometry of AcCh to $\alpha$-Bgtx Binding Sites. We have carefully examined the stoichiometry of high-affinity AcCh binding sites to $\alpha$-Bgtx binding sites of both receptorrich membrane fragments and detergent-solubilized, purified AcChR. As described in an earlier section, when ${ }^{125} \mathrm{I}-\alpha$-Bgtx binding assays with receptor-rich membrane fragments are carried out in the presence of $0.1 \%$ nonionic detergent, up to twice as many sites, relative to assays carried out in the absence of detergent, are revealed. The abscissa intercepts in Scatchard

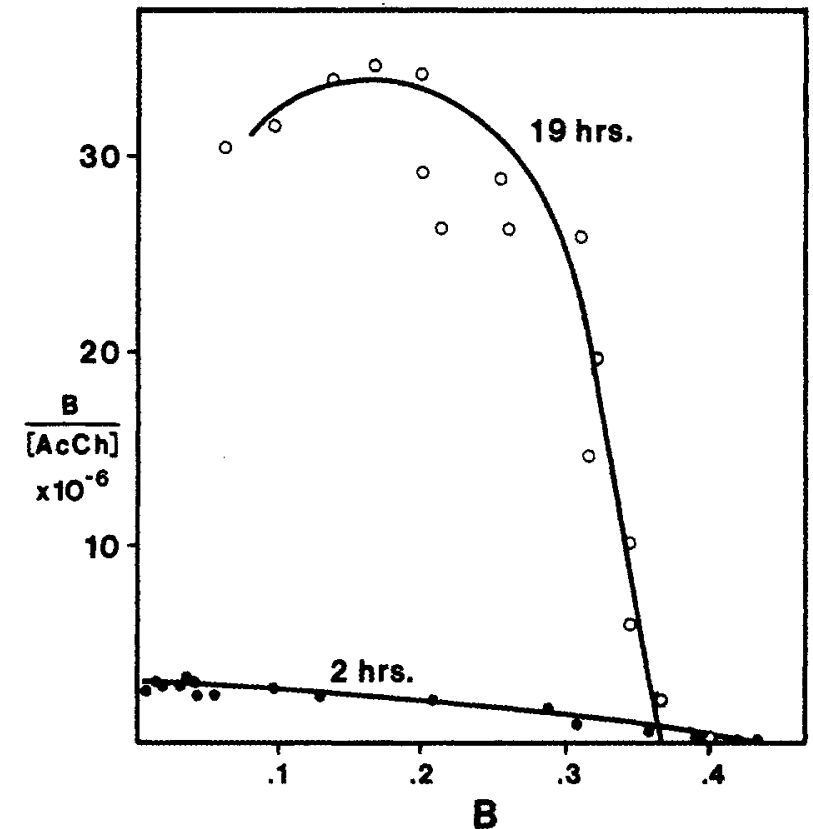

FIGURE 4: Comparison between Scatchard representations of $\left[{ }^{3} \mathrm{H}\right]$ AcCh binding data obtained by equilibrium dialysis of purified detergent-solubilized receptor (1.64 $\mu \mathrm{M}$ in $\alpha$-Bgtx binding sites) for 2 $(\odot)$ and $19 \mathrm{~h}(0)$. Note that $B_{\max }$ is close to 0.5 per $\alpha$-Bgtx site. $\bar{K}$ $=(4 \pm 1) \times 10^{-9} \mathrm{M}$ was estimated from a double-reciprocal plot by using the bigher $\mathrm{AcCh}$ concentration range of the upper curve.

plots from binding studies with membrane fragments, shown in Figures 1 and 2, indicate a $B_{\max }$ for $\mathrm{AcCh}$ close to 1 per $\alpha$-Bgtx site when the toxin binding data obtained in the absence of detergent were used. However, the $B_{\max }$ for $\mathrm{AcCh}$ would become about 0.5 per $\alpha$-Bgtx site if the number of $\alpha$-Bgtx sites assayed in the presence of detergent is used for calculations. This result is consistent with the maximum AcCh: $\alpha$-Bgtx site radio of about 0.5 obtained with the purified $\mathrm{AcChR}$ (Figures 3 and 4 ).

The question of whether the stoichiometry of agonist to $\alpha$-Bgtx binding sites under equilibrium conditions is 1 or 0.5 
has been a point of considerable discussion [for reviews, see Changeux (1981) and Taylor et al. (1983)]. It is pertinent to note that the investigators who have reported the stoichiometry of $\mathrm{AcCh}$ to $\alpha \cdot \mathrm{Bgtx}$ sites in membrane fragments to be 1 have assayed for toxin binding in the absence of detergent (Weber \& Changeux, 1974a; Sugiyama \& Changeux, 1975; Weiland et al., 1976; Neubig \& Cohen, 1979), while those who have reported it to be 0.5 appear to have used $0.1 \%$ Triton X-100 (Schimerlik et al., 1979).

In addition, an error in the determination of site stoichiometry can arise from inaccurate specific activity data provided by the suppliers of radiochemicals [see also Chang \& Bock (1977) and Neubig \& Cohen (1979)]. To demonstrate this point, we have summarized analyses of radioactive AcCh used in our laboratory over the years. While radiopurities (Lewis \& Eldefrawi, 1974) were all within acceptable levels, our analysis of the actual concentrations of AcCh, assayed spectrophotometrically by ferric-acethydroxamic acid complex formation (Hestrin, 1949; Chang \& Bock, 1979), yielded values that varied widely from batch to batch from those calculated from the specific activity and total radioactivity data provided by the manufacturer. Therefore, reliance on radiopurity and total radioactivity alone can introduce additional error in binding studies.

\section{Discussion}

This paper presents the first direct evidence that the data from the binding of $\left[{ }^{3} \mathrm{H}\right] \mathrm{AcCh}$ to the AcChR under conditions which ordinarily result in a state of overall equilibrium yield a binding curve that reflects nonequilibrium distributions of high-affinity and lower affinity binding conformers and exhibit hysteresis. If our $\left[{ }^{3} \mathrm{H}\right] \mathrm{AcCh}$ binding results were indeed the measure of the final thermodynamically most stable equilibrium state, it should be memoryless with respect to the steps preceding the final equilibrium and should result in one time-independent binding curve. However, this is not what we observed in our binding studies with both membrane-bound and purified AcChR (see Figures 1-4).

Analysis of our binding data indicates that when the concentration of total AcChR sites, $\left[R_{T}\right]$, is equal to or higher than the free concentration of $\mathrm{AcCh},\left[\mathrm{A}_{f}\right]$, i.e.

$$
\left[\mathbf{A}_{\mathrm{f}}\right] \leq\left[\mathbf{R}_{\mathrm{T}}\right]
$$

and when $\left[A_{f}\right]$ is in the low concentration range

$$
\left[\mathrm{A}_{\mathrm{f}}\right] \leq 10^{-7} \mathrm{M}
$$

then the degree of binding of $\left[{ }^{3} \mathrm{H}\right] \mathrm{AcCh}$ to the receptor not only is a function of the free concentration of $\left[{ }^{3} \mathrm{H}\right] \mathrm{AcCh}$ but also, quite unexpectedly, depends on the mode, i.e., the rate, of changing the concentration of $\left[{ }^{3} \mathrm{H}\right] \mathrm{AcCh}$.

Rapid addition of $\left[{ }^{3} \mathrm{H}\right] \mathrm{AcCh}$ to receptor-rich membrane fragments (pulse-mode addition) results in a relatively timeindependent, lower degree of binding at a given free $\left[{ }^{3} \mathrm{H}\right] \mathrm{AcCh}$ concentration (Figure 1, curve a) compared to addition by the dialysis mode (Figure 1, curves $b$ and $c$ ).

It was perplexing to find that while apparently time-independent binding values $(B)$ are obtained by pulse-mode additions of $\left[{ }^{3} \mathrm{H}\right] \mathrm{AcCh}$ to membrane fragments (see Figure 1, curve a, closed vs. open circles), a continuous increase in the binding of $\left[{ }^{3} \mathrm{H}\right] \mathrm{AcCh}$ in the low $\mathrm{AcCh}$ concentration range in observed (whereas $B_{\max }$ remained unchanged) when the same sample is dialyzed against the same free concentration of $\left[{ }^{3} \mathrm{H}\right] \mathrm{AcCh}$ found initially in the pulse-mode binding samples (see the legend of Figure 1, curves b anc c). These unexpected results indicate that the populations of $\mathrm{AcChR}$ in higher af- finity states increase during dialysis.

In the dialysis mode, the true equilibrium binding value at very low concentrations of $\mathrm{AcCh}(<10 \mathrm{nM})$ appears to be attainable only after long dialysis times, perhaps $40 \mathrm{~h}$, where protein denaturation may interfere (Figures 2 and 3 ). The linear relationship in the Scatchard plot was obtained by manipulating the experimental conditions: first, exposure of the receptor to high concentrations of $\left[{ }^{3} \mathrm{H}\right] \mathrm{AcCh}(1-20 \mu \mathrm{M})$ and second, dialysis to attain much lower free $\left[{ }^{3} \mathrm{H}\right] \mathrm{AcCh}$ concentrations (Figure 1, curve $d$ ). This experiment suggests that conversion to higher affinity conformations is accelerated by high AcCh concentrations. The dissociation constant, $\bar{K}$ $=5 \pm 1 \mathrm{nM}$, obtained from this linear Scatchard plot is comparable to that observed for high-affinity AcChR conformations, i.e., $2 \mathrm{nM}\left(\bar{K}_{\mathrm{eq}}=8 \mathrm{nM}\right)$ obtained from kinetic binding studies by Boyd \& Cohen (1980a). Therefore, the intermediate curved Scatchard plots (Figures 1-4) obtained either by pulse-mode or by dialysis-mode $\left[{ }^{3} \mathrm{H}\right] \mathrm{AcCh}$ addition cannot be analyzed in terms of overall equilibrium cooperativity since they appear to represent nonequilibrium distributions of rather long-lived, metastable high-affinity and lower affinity conformers and not to reflect equilibrium positive cooperativity [Fels et al., 1982; for reviews, see Karlin (1980) and Changeux (1981)].

Although only dialysis-mode $\left[{ }^{3} \mathrm{H}\right] \mathrm{AcCh}$ binding studies were carried out with the purified $\mathrm{AcChR}$, the indications of slow time-dependent and AcCh concentration-dependent transitions to higher affinity states qualitatively resemble those obtained with membrane-bound receptor (Figures 3 and 4). Our purified receptor is predominantly in the native dimeric (13 S) form covalently linked through disulfide bonds between two $\delta$ subunits (Chang \& Bock, 1977) and retains some indigenous phospholipids (Chang \& Bock, 1979). A rough estimation of the apparent dissociation constant $(\bar{K} \sim 0.2 \mu \mathrm{M})$ from the 2-h data points (closed circles of Figure 4) suggests that the initial dissociation constant, derived by extrapolation to the time of AcCh addition to the AcChR, may be larger than 0.2 $\mu \mathrm{M}$. Since the linear range of the $19-\mathrm{h}$ Scatchard plot (open circles of Figure 4) yielded an apparent $\bar{K}=4 \pm 1 \mathrm{nM}$, the final very high affinity state of the purified AcChR must have been induced by $\mathrm{AcCh}$ during dialysis rather than being a preexisting conformation.

Stoichiometries of AcCh Binding Sites. The effects of nonionic detergent on our ${ }^{125} \mathrm{I}-\alpha$-Bgtx binding assays of membrane fragments prepared in the presence of the Torpedo physiological concentration of $\mathrm{Ca}^{2+}(4 \mathrm{mM})$ (Moreau \& Changeux, 1976) are quite striking. As Table I shows, up to twice as many sites relative to those assayed in the absence of detergent are obtained in the membrane fractions with the highest specific $\alpha$-Bgtx binding activity (band 3) used for our $\left[{ }^{3} \mathrm{H}\right] \mathrm{AcCh}$ binding studies. There are at least two interpretations for this observation: contrary to other types of membrane preparation (Hartig \& Raftery, 1979), a portion of these microsacs may be "outside in" (i.e., the $\alpha$-Bgtx binding sites face the vesicle interior and therefore are not accessible to the toxin), or the detergent may loosen the membrane and thereby either expose the second sterically hindered $\alpha$-Bgtx binding site or increase its affinity. Many comparisons of the $\alpha$-Bgtx to AcCh stoichiometries in membrane-bound vs. detergentsolubilized receptor and the fact that detergent treatment of membrane fragments does not increase the total number of $\mathrm{AcCh}$ binding sites lead us to favor the latter interpretation. The small detergent effect ( $\sim 50 \%$ increase) observed in membrane-bound receptor from the upper band (band 1) taken from sucrose gradients may be attributable to loosening of the 
Table II: Analysis of Radiolabeled AcCh (Amersham) for Radiopurity and Ester Concentration

\begin{tabular}{|c|c|c|c|c|}
\hline \multirow{2}{*}{$\begin{array}{l}\text { Amersham } \\
\text { batch no. }\end{array}$} & \multirow{2}{*}{$\begin{array}{c}\text { reported } \\
\text { sp act. }(\mathrm{mCi} / \mathrm{mM})\end{array}$} & \multirow{2}{*}{$\begin{array}{l}\% \text { of AcCh } \\
\text { concn found }\end{array}$} & \multicolumn{2}{|c|}{$\begin{array}{l}\text { radiopurity } \\
(\%)^{d}\end{array}$} \\
\hline & & & reported & found \\
\hline 25 & 250 & 67 & 97 & 92 \\
\hline 27 & & & & 96 \\
\hline 28 & & 25 & & 81 \\
\hline 29 & 728 & 28 & 97 & \\
\hline 30 & 728 & 40 & 97 & \\
\hline 34 & 1100 & 35 & 97 & 96.5 \\
\hline 36 & 611 & 112 & & 98 \\
\hline $37^{b}$ & 55 & 123 & 97 & 98.5 \\
\hline 39 & 2700 & 124 & 98 & 96 \\
\hline 40 & & 39 & 98 & 94 \\
\hline $40^{\circ}$ & 992 & 41 & 98 & 94 \\
\hline \multicolumn{5}{|c|}{$\begin{array}{l}{ }^{a} \text { Batches } 25-36 \text { are }\left[{ }^{3} \mathrm{H}\right] \text { acetylcholine chloride. }{ }^{b} \text { Batch } 37 \text { is [ } 1 \\
{ }^{14} \mathrm{C} \text { acetylcholine chloride. } \\
\text { pected from the manufacturer's data. One vial ( } 1 \mathrm{mCi} \text { ) of AcCh was } \\
\text { dissolved in a known volume }(1-1.5 \mathrm{~mL}) \text { of distilled water, and the } \\
\text { exact concentration of AcCh was determined by the modified Hesterin } \\
\text { method (1949) described in Chang \& Bock (1979). Standard curves } \\
\text { were prepared by using recrystallized and dried acetylcholine bromide } \\
\text { d Radiochemical purity was assayed according to the method of Lewis } \\
\text { \& Eldefrawi (1974) immediately after the material was dissolved in } \\
\text { distilled water. Reported values are from the supplier's batch analysis } \\
\text { results. 'A replacement sample. }\end{array}$} \\
\hline
\end{tabular}

membrane through proteolysis, resulting in exposure of some of the second $\alpha$-Bgtx binding sites. It should be recalled that while the kinetics of binding of $\alpha$-Bgtx to Torpedo membrane-bound receptor are monophasic (Weber \& Changeux, 1974a; Weiland et al., 1976; Blanchard et al., 1979), the kinetics for solubilized receptor are biphasic (Blanchard et al., 1979), suggesting either that the affinity of one of the two $\alpha$-Bgtx sites on the receptor in the membrane is strongly altered by solubilization (Blanchard et al., 1979) or that a sterically hindered second site becomes available to $\alpha$-Bgtx upon detergent treatment. It should be noted here that our $\alpha$-Bgtx assays may have overestimated the $\alpha$-toxin sites by 10-20\%; since the purified AcChR has a relative molar mass of 250000 per monomer (Reynolds \& Karlin, 1978), its specific activity cannot exceed $8 \mathrm{~mol}$ of $\alpha$-toxin sites per mg of protein, if it contains two $\alpha$-toxin sites. However, our results and those from several other laboratories [see Table II in Karlin (1980)] indicate a specific activity of $10 \mathrm{nmol} / \mathrm{mg}$. Up to $20 \%$ overestimation in $\alpha$-Bgtx assays can also be inferred from our maximum $\left[{ }^{3} \mathrm{H}\right] \mathrm{AcCh}$ binding per $\alpha$-Bgtx site ratios $\left(B_{\max }\right)$ (see Figures 1-4). It may well be that the highly basic nature of the $\alpha$-Bgtx protein results in the relative underestimation of this protein concentration by the Lowry method.

Our $\left[{ }^{3} \mathrm{H}\right] \mathrm{AcCh}$ binding studies with membrane-bound receptor using carefully standardized $\left[{ }^{3} \mathrm{H}\right] \mathrm{AcCh}$ (Table II) show that the stoichiometry ratio of AcCh to $\alpha$-Bgtx sites is close to 1 (Figures 1 and 2). This ratio becomes about 0.5 if the number of $\alpha$-Bgtx sites is determined in the presence of detergent, in agreement with the ratio obtained with our solubilized and purified AcChR (Figures 3 and 4). It may very well be that there are two quite different binding sites for $\mathrm{AcCh}$ and other cholinergic ligands per receptor monomer (i.e., per two $\alpha$-Bgtx sites) (Delegeane \& McNamee, 1980; Wolosin et al., 1980; Dunne et al., 1983) and that only one of these can exhibit high affinity for AcCh when binding studies are performed under the conditions described here. It should be recalled that the nonequivalent nature of the two $\alpha$-toxin binding sites of the receptor has been demonstrated by showing that after disulfide reduction, only one of the $\alpha$-toxin sites is affinity alkylatable by a low concentration of [ $4-(N$-maleimido)benzyl] trimethylammonium (MBTA) or bromoacetyl-

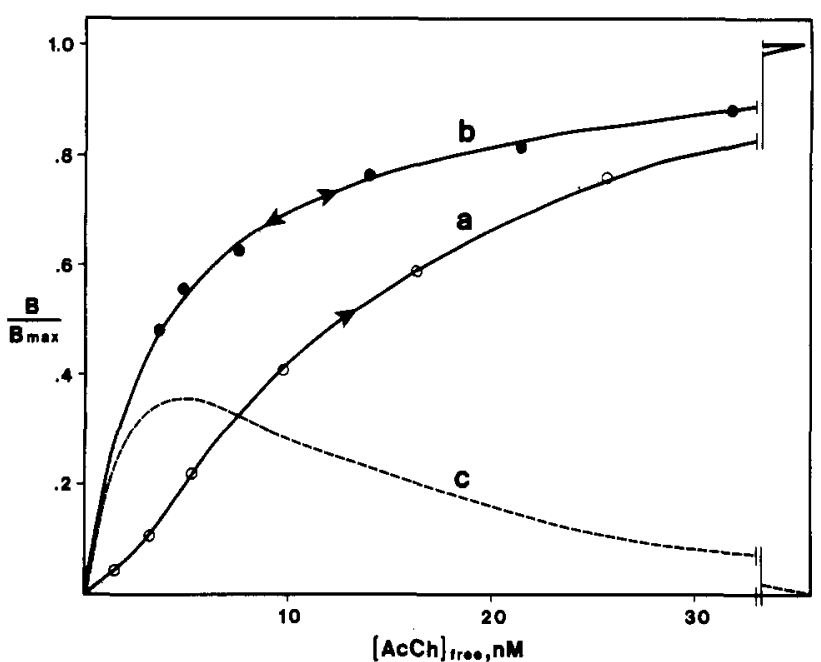

FIGURE 5: Difference curve (--) for the degree of binding of [ $\left.{ }^{3} \mathrm{H}\right] \mathrm{AcCh}$ to AcChR-rich membrane fragments as a function of $\mathrm{AcCh}$ concentration using two modes (rates) of applying AcCh. (a and b) Replots of the data presented in Scatchard form in Figure 1, curves $a$ and d, respectively. (c) Difference of curve b minus curve a $B / B_{\max }$ values goes through a maximum at $5 \mathrm{nM}$ concentration of free AcCh. Exposure to conditions of the open system with respect to AcCh (equilibrium dialysis), at a given $\mathrm{AcCh}$ concentration, changes the data points of curve a into the respective $B / B_{\max }$ values of curve $b$.

choline (Damle \& Karlin, 1978; Delegeane \& NcNamee, 1980).

Proposed Reaction Scheme. In Figure 6, we present a reaction scheme designed to rationalize the observed $\mathrm{AcCh}$ binding data. The two binding curves generated by the two extreme modes of applying AcCh presented in Figure 5 clearly demonstrate that two different binding pathways are traced: rapid mixing (pulse mode) leads to the lower curve (Figure 5, curve a); a slow mode of changing $\mathrm{AcCh}$ concentration by dialysis yields the upper curve (Figure 5, curve b). It can be seen that the maximum difference in the degree of binding occurs in the 4-5 $\mathrm{nM}$ free AcCh concentration range (Figure 5 , curve $\mathrm{c}$ ). At these low concentrations, the dominant reaction partner must be the high-affinity conformers.

In an attempt to describe the dialysis-mode binding data, a reaction model must account for the observed inequality of the free $\left[{ }^{3} \mathrm{H}\right] \mathrm{AcCh}$ concentration, $\left[\mathrm{A}_{\mathrm{f}}\right]$, which develops between the inside and the outside of the dialysis bag (see Figure 2) even when the initial conditions are $\left[A_{f}\right]_{\text {in }}=\left[A_{f}\right]_{\text {out }}$. The inequality (eq 5 ) can arise from the additional binding of $\mathrm{AcCh}$

$$
\left[\mathrm{A}_{\mathrm{f}}\right]_{\text {in }}<\left[\mathrm{A}_{\mathrm{f}}\right]_{\text {out }}
$$

to higher affinity states of the AcChR, generated by the conversion of unoccupied low-affinity sites to high-affinity sites, $\mathbf{R}_{\mathrm{l}} \cdot \mathbf{R}_{\mathrm{l}} \rightleftharpoons \mathbf{R}_{\mathrm{h}} \cdot \mathbf{R}_{\mathrm{h}}$, or unoccupied high-affinity sites to still higher affinity sites, $A R_{v h} \cdot R_{h} \rightleftharpoons A R_{v h} \cdot R_{v h}$ (see Figure 6). Such newly created high-affinity sites would now bind a part of the remaining AcCh such that the free $\mathrm{AcCh}$ concentration inside the dialysis bag decreases below the initial value. In this situation, the AcCh flux through the dialysis membrane is rate limiting for the overall rate of net AcCh binding to AcChR.

When the most stable state $\left(R_{\mathrm{vh}}\right)$ is the final very high affinity conformer associated with the individual equilibrium constant, $K_{\mathrm{vh}} \sim 10^{-9} \mathrm{M}\left(K_{\mathrm{vh}}<\bar{K}=5 \times 10^{-9} \mathrm{M}\right)$, the conformers $\mathrm{R}_{\mathrm{h}}$ must have $K_{\mathrm{h}}$ values which are larger than $10^{-9}$ $M$, perhaps $\sim 10^{-7} \mathrm{M}$ [see Boyd \& Cohen (1980)]. Hence, at equilibrium, the concentrations of the intermediate $A R_{h}$ state may be negligible compared to those of $\mathrm{AR}_{\mathrm{vh}}$.

Since our data suggest that cooperative interactions between at least two $\mathrm{AcCh}$ binding sites exist, a minimum reaction 


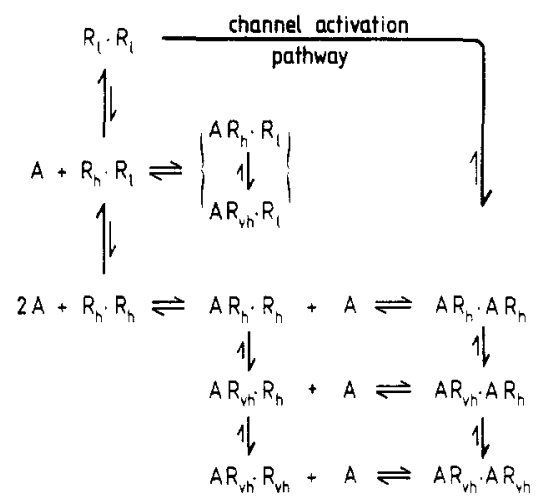

FIGURE 6: Proposed reaction scheme of $\mathrm{AcCh}$ binding to AcChR to account for the difference in the AcCh binding profile resulting from "pulse-mode addition" (closed system with respect to $\mathrm{AcCh}$ ) and "dialysis-mode addition" (open system). The simple bimolecular processes are represented by the horizontal sequences, whereas the vertical steps model the various slow structural isomerizations. $\mathbf{R}_{\mathbf{l}}$, low-affinity conformer $\left(10^{-6} \mathrm{M}<\bar{K}<10^{-4} \mathrm{M}\right) ; \mathrm{R}_{\mathrm{h}}$, high-affinity conformer $\left[K \sim 5( \pm 1) \times 10^{-9} \mathrm{M}\right] ; \mathbf{R}_{\mathrm{h}} \cdot \mathbf{R}_{\mathbf{l}}$, hybrid form of the two binding sites. The thick arrows indicate the preferential position of the isomerization equilibria. Large upper arrow indicates the channel activation pathway. At high $\mathrm{AcCh}$ concentrations $\left(>10^{-6} \mathrm{M}\right)$, the low-affinity conformer, $\mathbf{R}_{\mathbf{1}}$, is directly involved in the binding which results in channel opening and is subsequently transformed to its high-affinity state. At low AcCh concentrations $\left(<10^{-6} \mathbf{M}\right)$, the $\mathbf{R}_{\mathrm{h}}$ conformer is the dominant direct reaction partner for AcCh and thus constitutes the direct route of the high-affinity state pathway of the bottom part of the scheme. Pulse-mode addition of $\mathrm{AcCh}$ (closed system) favors the $A R_{h} \cdot R_{1}$ and $A R_{v h} \cdot R_{1}$ binding states, whereas dialysis-mode addition (open system) ultimately leads to the $\mathrm{AR}_{\mathrm{vh}} \cdot \mathrm{AR}_{\mathrm{vh}}$ conformer.

scheme consistent with the dialysis data with respect to the inequality (eq 5) and the high-affinity binding stoichiometry (maximum of one $\mathrm{AcCh}$ per monomer) requires that receptor dimers (13 S), $\mathbf{R} \cdot \mathbf{R}$, must be involved. It should be recalled that $\left[{ }^{3} \mathrm{H}\right] \mathrm{AcCh}$ equilibrium binding to the solubilized or purified monomer form (9 S) and AcChR from electric eel yielded a linear Scatchard plot with $\bar{K}_{\mathrm{d}} \sim 45-60 \mathrm{nM}$ (Meunier \& Changeux, 1973; Chang \& Neumann, 1976).

The inequality eq 5 also indicates that the $\mathrm{AcCh}$-induced structural transitions are faster than the AcCh influx into the dialysis bag at low $\mathrm{AcCh}$ concentrations under the conditions of eq 3 and 4 . The rate of the conformationally controlled net AcCh binding by the high-affinity receptor conformers is the reference for the different experimental rates of increasing the AcCh concentration. When the rate of AcCh increase is slower than the structural transitions, as appears to be the case in the dialysis mode, the final binding equilibrium can be slowly reached.

When the $\mathrm{AcCh}$ concentration is increased at a rate more rapid than the conformationally controlled AcCh binding (pulse mode), rather long-lived nonequilibrium distributions of states with fewer occupied AcCh binding sites are maintained. Because these metastable nonequilibrium distributions depend on the rate of which AcCh concentration is increased, they must result from rate processes. In any case, the pulse-mode data suggest that the overall transitions from $R_{1} \cdot R_{1}$ to more high-affinity conformers can be "interrupted". On an elementary scale, the overall equilibrium $R_{l} \cdot R_{1} \leftrightharpoons R_{h} \cdot R_{h}$ very likely involves the intermediate form $R_{h} \cdot R_{1}$. This hybrid $R_{h} \cdot R_{l}$, as a part of the sequence

$$
\mathbf{R}_{1} \cdot \mathbf{R}_{\mathbf{l}} \rightleftharpoons \mathbf{R}_{\mathrm{h}} \cdot \mathbf{R}_{\mathbf{l}} \rightleftharpoons \mathbf{R}_{\mathrm{h}} \cdot \mathbf{R}_{\mathrm{h}}
$$

represents a suitable branching point where different rate processes can occur according to the partial scheme

$$
\begin{aligned}
& R_{1} \cdot R_{1} \\
& \quad 1 k \\
& A+R_{h} \cdot R_{1} \rightleftharpoons A R_{h} \cdot R_{1} \rightleftharpoons A R_{n h} \cdot R_{1} \\
& \quad l \\
& R_{h} \cdot R_{h}
\end{aligned}
$$

In the reaction model 7, the binding of $\mathrm{AcCh}$ to the conformer $\mathbf{R}_{h}$ of the hybrid $\mathbf{R}_{h} \cdot \mathbf{R}_{l}$ conserves the adjacent low-affinity state. The longevity of this low-affinity conservation suggests that, in addition to simple AcCh binding, structural transitions to complexes with longer lifetimes, $\mathrm{AR}_{\mathrm{vh}} \cdot \mathrm{R}_{\mathrm{l}}$, may also be involved.

Because the apparent freezing-in of low-affinity states is initiated by a bimolecular step, the concentrations of the complexes of this pathway depend on both the AcCh and receptor concentrations. In the pulse mode, the binding of AcCh to the hybrid, $A+R_{h} \cdot R_{1} \rightleftharpoons A R_{h} \cdot R_{1}$, appears to be faster than the intramolecular transition, $\mathrm{R}_{\mathrm{h}} \cdot \mathrm{R}_{1} \leftrightharpoons \mathrm{R}_{\mathrm{h}} \cdot \mathbf{R}_{\mathrm{h}}$. Furthermore, under closed-system conditions with respect to $\mathrm{AcCh}$ where little fluctuation of the free $\mathrm{AcCh}$ concentration exists, the conversion to the final $R_{v h}$ conformation may be extremely slow. Thus, under such conditions of fixed total AcCh concentration, as opposed to the open system of the dialysis mode, nonequilibrium distributions with less $\mathrm{AcCh}$ bound states can be maintained for a very long time. The low-affinity conservation pathway can therefore be considered a frozen-in or dead-end pathway.

Subsequent transfer of these metastable nonequilibrium distributions to the open-system conditions afforded by dialysis (see Figure 1, curves $b$ and $c$ ) is assumed to enhance the coupling of the hybrid to the intramolecular step $R_{h} \cdot R_{1} \rightleftharpoons$ $R_{h} \cdot R_{h}$ of the reaction scheme (eq 6). The reaction steps $2 A$ $+R_{h} \cdot R_{h} \rightarrow A R_{v h} \cdot R_{v h}+A \rightarrow A R_{v h} \cdot A_{v h}$, describing the transient development of the inequality eq 5 , presumably give rise to larger driving forces to diverge the complexes from the low-affinity conservation pathway (eq 7) and induce a maximum shift to the side of the high-affinity complexes.

The inequality relationship only develops when the reaction system is in the range of validity of the relations 3 and 4 . At high $\mathrm{AcCh}$ concentrations, $[\mathrm{A}] \gg\left[\mathrm{R}_{\mathrm{T}}\right]$, both dialysis and pulse modes yield the same (equilibrium) $B_{\max }$ value. Thus, the occurrence of a finite difference in $B$ values (Figure 5, curve c) between the pulse and dialysis modes can be attributed to a rate phenomenon which may be understood on the basis of competition between bimolecular and intramolecular reaction steps.

Compared to previous cyclic schemes (eq 1) [see, e.g., Katz $\&$ Thesleff (1957)], the present reaction model (Figure 6) for the distribution of low- and high-affinity receptor conformers contains hybrid forms, a low-affinity conservation pathway, and ligand-induced conformational changes on the level of the high-affinity receptor conformers.

Hysteresis. When $\mathrm{AcChR}$ is exposed to cyclic changes of increasing and decreasing $\mathrm{AcCh}$ concentrations under the constraints of the relations in eq 3 and 4 , and resulting binding data give rise to a very pronounced hysteresis loop (Figure 7). The lower hysteresis branch (Figure 7, curve a) is traced when increasing amounts of $\mathrm{AcCh}$ are added by the pulse mode to aliquots of $\mathrm{AcChR}$ until, at $\left[\mathrm{A}_{\mathrm{f}}\right]>10^{-6} \mathrm{M}$, the maximum number of $\mathrm{AcChR}$ is present as AcCh-bound high-affinity conformers. When this equilibrated system is now diluted with respect to $\mathrm{AcCh}$ by dialysis, the upper branch of the hysteresis loop (Figure 7, curve b) is traced. Since any point on the lower branch (Figure 7, curve a) can be converted by dialysis to its respective $B / B_{\max }$ value of Figure 7, curve b, this upper branch must represent the equilibrium. Consequently, the lower 


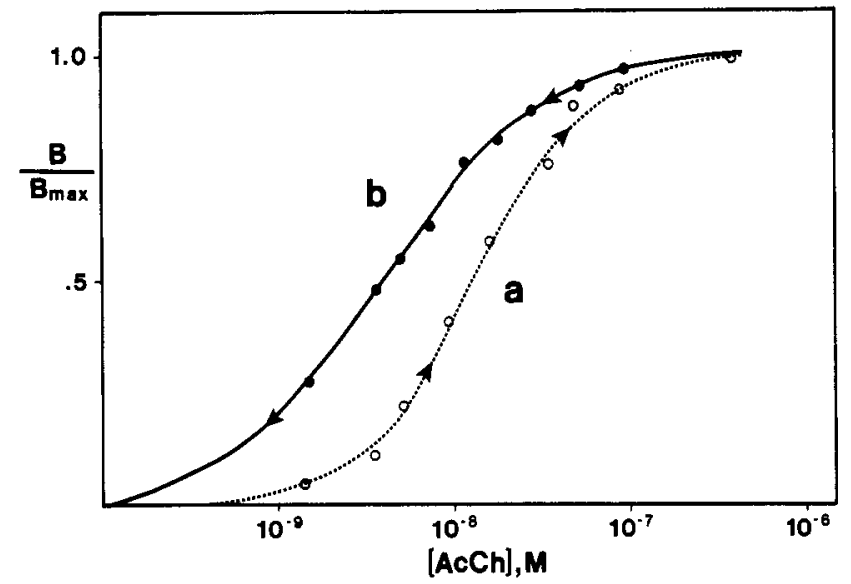

FIGURE 7: Degree of binding of $\left[{ }^{3} \mathrm{H}\right] \mathrm{AcCh}\left(B / B_{\max }\right)$ at $4{ }^{\circ} \mathrm{C}$ to Torpedo receptor rich membrane fragments as a function of cyclic changes in the concentration of $\mathrm{AcCh}$ on a logarithmic scale, showing hysteresis. (a) (O) Binding curve obtained by pulse-mode addition of $\left[{ }^{3} \mathrm{H}\right] \mathrm{AcCh}$ to the receptor, followed by ultracentrifugation to determine bound and free $\left[{ }^{3} \mathrm{H}\right] \mathrm{AcCh}$ concentrations (see Figure 1, curve a). (b) ( ) Binding data obtained by incubation of AcChR $(0.48$ $\mu \mathrm{M}$ in $\alpha$-Bgtx sites) with high AcCh concentrations (1-20 $\mu \mathrm{M})$ followed by dialysis against initially AcCh-free buffer to reach final free $\mathrm{AcCh}$ concentrations of 3-400 $\mathrm{nM}$ (see Figure 1, curve d). The curve is a calculated line for $\bar{K}=5 \times 10^{-9} \mathrm{M}$.

branch of apparently time-independent binding data must represent long-lived metastable nonequilibrium distributions of receptor conformers.

On a time scale of at least $20 \mathrm{~h}$, the hysteresis loop is time independent and may thus be subjected to thermodynamic analysis (Katchalsky \& Neumann, 1972; Everett, 1967; Neumann, 1973). The loop size is a measure of the irreversibly dissipated Gibbs free energy $\left(\Delta G_{\mathrm{irr}, P, T}\right)$ and the entropy production $\left(\Delta_{f} S\right)$ during one concentration-dilution cycle at constant temperature $(T)$ and pressure $(P)$.

$$
\Delta G_{\mathrm{irr}, P, T}=-T \Delta_{i} S
$$

The term $\Delta G_{\text {irr }}$ is also a measure of the stability of the metastable nonequilibrium distributions obtained in the pulse mode. As outlined elsewhere (Neumann, 1973), the work dissipation may be expressed as

$$
\Delta G_{\mathrm{irt}}=-2.3 R T \oint \beta \mathrm{d}\left(\log a_{\mathrm{A}}\right)
$$

where $a_{\mathrm{A}}$ is the thermodynamic activity of $\mathrm{AcCh}, \beta$ is $B / B_{\max }$ (the degree of $\mathrm{AcCh}$ binding) $(0 \leq \beta \leq 1)$, and $R$ is the universal gas constant.

At the low AcCh concentrations where the hysteresis exists, we may replace $a_{\mathrm{A}}$ by [A] ([A] in units of moles per liter). Now the cyclic integral may be expressed as

$$
\oint \beta \mathrm{d}\left(\log a_{\mathrm{A}}\right)=\int_{0}^{\infty} \Delta \beta \mathrm{d}(\log [\mathrm{A}])=F
$$

where $F$ is the area of the hysteresis loop; $\Delta \beta=\Delta\left(B / B_{\max }\right)$ is defined in the context of the description of Figure 5. From Figure 7 , we obtain $F=0.53( \pm 0.02)$. Since at $4^{\circ} \mathrm{C} T=$ $277.15 \mathrm{~K}$ and $R T=2.305 \mathrm{~kJ} \mathrm{~mol}^{-1}$, we have $\Delta G_{\mathrm{irr}}=-2.8$ $( \pm 0.1) \mathrm{kJ} \mathrm{mol}^{-1}$ and $\Delta_{\mathrm{h}} S=10.1( \pm 0.4) \mathrm{J} \mathrm{K}^{-1} \mathrm{~mol}^{-1}$.

The thermodynamic dissipation quantities $\Delta G_{\text {irr }}$ and $\Delta_{l} S$ represent mean values of the conformer distributions. The numerical value of the isoelectric point of Torpedo californica AcChR (Raftery et al., 1972), $\mathrm{pI}=4.9$, and the relatively high binding capacity of the isolated $\mathrm{AcChR}$ dimer for $\mathrm{Ca}^{2+}$ ions (Dorogi et al., 1981) suggest a relatively high surface charge density at a neutral $\mathrm{pH}$ value. Thus, as in other examples of macromolecular hysteresis, electrostatic aspects may also dominate the hysteretic binding of the cationic ligand $\mathrm{AcCh}$ to AcChR.

Physiological Significance. Under the concentration constraints eq 3 and 4 , the exposure of $\mathrm{AcChR}$ to pulses of $\mathrm{AcCh}$ stabilizes low-affinity conformations and saves them from conversions to all high-affinity complexes. Functionally, the low-affinity states are involved in the ion flux activation whereas the high-affinity conformations are associated with inactivation or desensitization of the ion transport. The results of the present study suggest that the conversion of high-affinity states at low $\mathrm{AcCh}$ concentrations may be largely reduced if the AcCh appears in the form of pulses. On the other hand, a continuous flow of $\mathrm{AcCh}$ will eventually desensitize all receptors. Therefore, their capacity to endure in long-lived metastable states may be a "saving device" for the activatable low-affinity conformations of the AcChR.

The hysteresis which results from the occurrence of longlived metastable states classified the AcChR as a macromolecular memory system, indicating the receptor's previous mode of exposure to $\mathrm{AcCh}$.

At present, physiological implications of the capability to develop metastable states and hysteresis-memory in the binding of $\mathrm{AcCh}$ to the $\mathrm{AcChR}$ remain on a purely speculative level. AcCh-induced structural changes and the extent of flux inactivation could serve as the information which indicates whether a synapse or a part of it had previously been used in signal generation by AcCh pulses [see Neumann \& Bernhardt (1981)]. In any case, the hysteresis classifies the acetylcholine receptor as the molecular entity that carries the imprint (Katchalsky \& Neumann, 1972) of nerve impulse induced release of $\mathrm{AcCh}$ pulses.

\section{Acknowledgments}

This paper is dedicated to the memory of Professor David Nachmansohn, the pioneer of studies of the biochemical and molecular basis of bioelectricity, our mentor, whose enthusiasm and encouragement have been an inspiration to us over the years. We miss him greatly. We thank Winsome F. Lumsden-Walker for excellent technical assistance.

Registry No. AcCh, 51-84-3; Lubrol WX, 11138-41-3; Triton $\mathrm{X}-100,9002-93-1$.

\section{References}

Adams, P. R. (1981) J. Membr. Biol. 58, 161-174.

Barrantes, F. J. (1978) J. Mol. Biol. 124, 1-26.

Bernhardt, J., \& Neumann, E. (1978) Proc. Natl. Acad. Sci. U.S.A. 75, 3756-3760.

Bever, C. T., Jr., Chang, H. W., Penn, A. S., Jaffe, I. A., \& Bock, E. (1982) Neurology 32, 1077-1082.

Blanchard, S. G., Quast, U., Reed, K., Lee, T., Schimerlik, M. I., Vandlen, R. L., Claudio, T., Strader, C. D., Moore, H.-P. H., \& Raftery, M. A. (1979) Biochemistry 18, 1875-1883.

Blanchard, S. G., Dunn, S. M. J., \& Raftery, M. A. (1982) Biochemistry 21, 6258-6264.

Boyd, N. D., \& Cohen, J. B. (1980a) Biochemistry 19, 5344-5353.

Boyd, N. D., \& Cohen, J. B. (1980b) Biochemistry 19, 5353-5358.

Calderbank, A., \& Ghosh, R. (1955) Chem. Ind. (London) $118,637$.

Chang, H. W., \& Newman, E. (1976) Proc. Natl. Acad. Sci. U.S.A. $173,3364-3368$. 
Chang, H. W., \& Bock, E. (1977) Biochemistry 16, 4513-4520.

Chang, H. W., \& Bock, E. (1979) Biochemistry 18, 172-179.

Chang, H. W., \& Bock, E. (1980) Anal. Biochem. 104, $112-117$.

Changeux, J.-P. (1981) Harvey Lect. 75, 81-254.

Chesnut, T. J. (1983) J. Physiol. (London) 336, 229-241.

Clark, R. B., \& Adams, P. R. (1981) Biophys. J. 33, 16 a.

Conti-Tronconi, B. M., \& Raftery, M. A. (1982) Annu. Rev. Biochem. 51, 499-530.

Damle, V. N., \& Karlin, A. (1978) Biochemistry 17, 2039-2045.

Damle, V. N., Hamilton, S., Valderrama, R., \& Karlin, A. (1976) Pharmacologist 18, 146.

Delegeance, A. M., \& McNamee, M. G. (1980) Biochemistry 19, 890-895.

Dorogi, P. L., Chang, H. W., Moss, K., \& Neumann, E. (1981) Biophys. Chem. 14, 91-100.

Dunn, S. M. J., Conti-Tronconi, B. M., \& Raftery, M. A. (1983) Biochemistry 22, 2512-2518.

Eldefrawi, M. E., Eldefrawi, A. T., Mansour, N. A., Daly, J. A., Witkop, B., \& Albuquerque, E. X. (1978) Biochemistry $17,5474-5484$.

Ellman, G. L., Courtney, K. D., Andres, V., \& Featherstone, R. M. (1961) Biochem. Pharmacol. 7, 88-95.

Everett, D. H. (1967) in The Solid Gas Interface (Flood, E. A., Ed.) Vol. 2, pp 1055-1113, Marcel Dekker, New York.

Fels, G., Wolff, E. K., \& Maelicke, A. (1982) Eur. J. Biochem. 127, 31-38.

Feltz, A., \& Trautmann, A. (1982) J. Physiol. (London) 322, 257-272.

Fiukuto, T. R., \& Stafford, E. M. (1957) J. Am. Chem. Soc. 79, 6083-6085.

Gibson, R. E. (1976) Biochemistry 15, 3890-3901.

Hartig, P. R., \& Raftery, M. A. (1979) Biochemistry 18, 1146-1150.

Heidmann, T., \& Changeux, J.-P. (1979) Eur. J. Biochem. 94, 281-296.

Hestrin, S. (1949) J. Biol. Chem. 180, 249-261.

Karlin, A. (1980) in Cell Surface Reviews (Poste, G., Nicolson, G. L., \& Cotman, C. W., Eds.) pp 191-260, Elsevier, Amsterdam.

Karlin, A., Weill, C., McNamee, M., \& Valderrama, R. (1976) Cold Spring Harbor Symp. Quant. Biol. 40, 203-210.

Kasai, M., \& Changeux, J.-P. (1971) J. Membr. Biol. 6, 1-80.

Katchalsky, A., \& Neumann, E. (1972) Int. J. Neurosci. 3, 175-182.

Katz, B. (1969) The Release of Neural Transmitter Substances, p 55, Liverpool University Press, Liverpool, U.K.

Katz, B., \& Thesleff, S. (1957) J. Physiol. (London) 138, 63-80.

Lewis, M. K., \& Eldefrawi, M. E. (1974) Anal. Biochem. 57, 588-592.

Lowry, O. H., Rosenbrough, N. J., Farr, A. L., \& Randall, R. J. (1951) J. Biol. Chem. 193, 265-275.

Magazanik, L. G., \& Vyskocil, F. (1976) in Motor Innervation of Muscle (Thesleff, S., Ed.) pp 151-176, Academic Press, New York.
Meunier, J.-C., \& Changeux, J.-P. (1973) FEBS Lett. 32, 143-148.

Moreau, M., \& Changeux, J.-P. (1976) J. Mol. Biol. 106, 457-467.

Nachmansohn, D. (1959) Chemical and Molecular Basis of Nerve Activity, p 403, Academic Press, New York.

Nastuk, W. L. (1977) in Synapse (Cottrell, G. A., \& Usherwood, P. N. R., Eds.) pp 177-201, Academic Press, New York.

Neubig, R. R., \& Cohen, J. B. (1979) Biochemistry 18, 5464-5475.

Neubig, R. R., \& Cohen, J. B. (1980) Biochemistry 19, 2770-2779.

Neubig, R. R., Krodel, E. K., Boyd, N. D., \& Cohen, J. B. (1979) Proc. Natl. Acad. Sci. U.S.A. 76, 690-694.

Neubig, R. R., Boyd, N. D., \& Cohen, J. B. (1982) Biochemistry $21,3460-3467$.

Neumann, E. (1973) Angew. Chem., Int. Ed. Engl. 12, 356-369.

Neumann, E., \& Bernhardt, J. (1981) J. Physiol. (Paris) 77, 1061-1072.

O'Brien, R. D., \& Gibson, R. E. (1975) Arch. Biochem. Biophys. 169, 458-463.

Paulus, H. (1969) Anal. Biochem. 32, 91-100.

Popot, J. L., Sugiyama, H., \& Changeux, J.-P. (1976) J. Mol. Biol. 106, 469-483.

Quest, U., Schimerlik, M., Lee, T., Witzemann, V., Blanchard, S., \& Raftery, M. A. (1978) Biochemistry 17, 2405-2415.

Raftery, M. A., Schmidt, J., \& Clark, D. G. (1972) Arch. Biochem. Biophys. 152, 882-886.

Raftery, M. A., Vandlen, R. L., Reed, K. L., \& Lee, T. (1975) Cold Spring Harbor Symp. Quant. Biol. 40, 193-202.

Rang, H. P., \& Ritter, J. M. (1970) Mol. Pharmacol. 6, 357-382.

Reynolds, J. A., \& Karlin, A. (1978) Biochemistry 17, 2035-2038.

Sakmann, B., Patlak, J., \& Neher, E. (1980) Nature (London) 286, 71-73.

Schiebler, W., Lauffer, L., \& Hucho, F. (1977) FEBS Lett. $81,39-42$.

Schimerlik, M., Quast, U., \& Raftery, M. A. (1979) Biochemistry 18, 1884-1890.

Sine, S., \& Taylor, P. (1979) J. Biol. Chem. 254, 3315-3325.

Sobel, A., Weber, M., \& Changeux, J.-P. (1977) Eur. J. Biochem. 80, 215-224.

Sugiyama, H., \& Changeux, J.-P. (1975) Eur. J. Biochem. $55,505-515$.

Taylor, P., Brown, R. D., \& Johnson, D. A. (1983) Curr. Top. Membr. Transp. 18, 407-445.

Weber, M., \& Changeux, J.-P. (1974a) Mol. Pharmacol. 10, 1-14.

Weber, M., \& Changeux, J.-P. (1974b) Mol. Pharmacol. 10, $15-34$.

Weiland, G., Georgia, B., Wee, V. T., Chignell, C. F., \& Taylor, P. (1976) Mol. Pharmacol. 12, 1091-1105.

Weiland, G., Georgia, B., Lappi, S., Chignell, C. F., \& Taylor, P. (1977) J. Biol. Chem. 252, 7648-7656.

Wolosin, J. M., Lyddiatt, A., Dolly, J. O., \& Barnard, E. A. (1980) Eur. J. Biochem. 109, 495-505. 